\title{
Fiscal Policy in the New Open Economy MACROECONOMICS AND PROSPECTS FOR Fiscal Policy CoORdination
}

\section{LEONOR COUTINHO}

CEPS Working Documents are published to give an indication of the work within CEPS' various research programmes and to stimulate reactions from other experts in the field. Unless otherwise indicated, the views expressed are attributable only to the author in a personal capacity and not to any institution with which she is associated.

ISBN 92-9079-440-2

Available for free downloading from the CEPS website (http://www.ceps.be)

(c) Copyright 2003, CEPS 


\title{
Fiscal Policy in the New Open Economy Macroeconomics and Prospects for Fiscal Policy Coordination
}

\author{
Leonor Coutinho*
}

\begin{abstract}
This paper reviews the analysis of fiscal policy in the new open economy macroeconomics literature, in view of increasing interest in the question of transmission and coordination of policies across countries, stirred by developments in this literature and by the formation of the euro area. The analysis focuses on two main points: (i) the identification of welfare spillover effects to third countries; and (ii) the assessments made so far of the potential gains from pursuing non-cooperative and cooperative fiscal stabilisation policies. Regarding welfare spillovers, some additional results are derived to examine whether the exchange rate regime (flexible or fixed) matters for the size of these spillovers, and whether the type of policy pursued (balanced-budget or debtfinanced) matters. Fixed exchange rates only seem to postpone the costs from the short to the long run, but the type of policy is crucial in determining the welfare impact of fiscal expansions. With respect to policy coordination, attention is drawn to the need to reflect on a potential role for fiscal policy as a stabilisation tool, and on possible interactions between fiscal and monetary policy.
\end{abstract}

JEL classification: F41, F42, E42

Keywords: Fiscal policy, Spillovers, Stabilisation, Coordination

${ }^{*}$ I am grateful to Daniel Gros for useful comments and suggestions and to the participants of the Centre for European Policy Studies (CEPS) Macroeconomic Policy Group 2003 meetings. I am also indebted to Giovanni Ganelli for his comments and suggestions and to Matthew Canzoneri for useful advice. This research was supported through a European Community Marie Curie Fellowship Contract $\mathrm{N}^{\circ} \mathrm{HPMF}-\mathrm{CT}-$ 2002-01705. The views expressed here and any remaining errors are mine solely. 


\section{Introduction}

The collapse of the Bretton Woods system of fixed-exchange rates instigated the first significant body of research on the international transmission of shocks and the need for policy coordination. This first generation research was based on the old Keynesian models that did provide a theoretical rationale for policy coordination, but could not generate quantitatively large coordination gains (see Canzoneri et al., 2002a, and references therein). Recently the formation of the euro area and the emergence of the "new open economy macroeconomics" (NOEM) literature has stirred interest again in the transatlantic transmission and coordination of monetary and fiscal policies. The NOEM literature is the first influential attempt to substitute the Mundell-Fleming-Dornbush (MFD) model as the workhorse framework for analysing the international transmission by a micro-founded framework. Although building on the MFD lineage, by considering nominal rigidities, the NOEM framework provides a rationale for such rigidities by introducing monopolistic behaviour of economic agents, and substitutes the ad-hoc evaluation of alternative policy regimes by rigorous welfare comparisons.

Since the publication of the seminal Redux model of Obstfeld and Rogoff (1995), many contributions have tried to understand more deeply the effects of alternative monetary policies and their potential spillover effects, by changing some key assumptions of the Redux. However, little attention has been paid so far to the effects of fiscal policy and fiscal policy coordinaton. ${ }^{1}$ The sign of the spillovers has been identified in some models, but the estimation of the actual gains from fiscal coordination has not received the same rigorous treatment that has been devoted to the study of the gains from monetary policy coordination. Meyer et al. (2002), list several reasons that could explain why fiscal policy has been mostly overlooked in this area. The first reason they put forward is the fact that,

\footnotetext{
${ }^{1}$ A survey of NOEM models, focusing on monetary policy transmisson can be found in Lane (2001). Ganelli and Lane (2002) survey also contributions that address fiscal policy issues. This paper refers to some of the research on fiscal policy surveyed by these authors and reviews additional one.
} 
during the 1970's, the criticism of stabilisation policies in general fell most heavily on fiscal policy simply because fiscal stabilisation had played a major role during the 50's and 60's. In addition several specific drawbacks have been attributed to the use of fiscal policy as a stabilisation tool. The most frequently cited are: its inflexibility to be changed in a timely fashion, the potentially small effects of temporary measures, such as temporary tax changes, and the fact that fiscal policy is often used for political goals.

Referring specifically to policy coordination between the euro area and the United States, Canzoneri et al. (2002b) emphasise that for reasons similar to those listed above "both the theoretical case and the political momentum for transatlantic policy coordination seem to be lacking at present...". ${ }^{2}$ Nevertheless their empirical estimates (albeit imprecise) suggest that there may be sizeable effects of US fiscal shocks on EU consumption and output. They suggest treating fiscal expansions/contractions as exogenous shocks to which the monetary authority has to react. Evaluating the need for policy coordination would then boil down to assessing whether these additional shocks make it more or less desirable for the monetary authorities to coordinate across the Atlantic.

On the other hand, some of the drawbacks of direct fiscal policy coordination could be overcome. To tackle the problem of timeliness, Meyer et al. (2002) suggest that more emphasis be given to the design of "automatic stabilisers". They also highlight other arguments in support of fiscal policy stabilisation. Even if fiscal policy changes take longer to be put in place, they affect the economy faster than monetary policy. In addition, in some cases fiscal stabilisation may be the only viable alternative. In the case of Japan, for instance, where economic activity has been weak and short-term interest rates have reached a zero lower bound, fiscal policy seems the only way to stimulate economic activity. Additionally, in EMU where monetary policy has been delegated to a common independent institution, fiscal policy emerges as the only flexible tool available to individual economies

\footnotetext{
${ }^{2}$ To this has also contributed the fact that the external representation of the euro area in international fora has remained so decentralised. Although the new draft Constitution for the European Union constitutes a base for ensuring a common voice, it remains undefined who will represent that voice (see European Convention, 2003).
} 
for stabilising country-specific or asymmetric shocks. Whether there is a need for fiscal coordination among EMU member countries remains therefore a fundamental question. Even if the Stability and Growth Pact (SGP), which binds governments in EMU to maintain their budget deficits below $3 \%$, remains in place to address the problem of the expansionary bias in fiscal policy (see Canzoneri et al. 2002b, for a discussion of the presence of a fiscal spending bias in NOEM), automatic stabilisers and discretionary policy within the limits of the SGP could be designed more optimally.

In theory, as well as in practice, the key requirement for policy coordination to be desirable is the presence of externalities. Even though the NOEM literature has paid relatively little attention to fiscal policy, some results can already be inferred regarding the potential signs and magnitudes of fiscal spillovers. This paper reviews the analysis of fiscal policy in recent new open economy macroeconomic models, focusing on two main points. The first is the identification of potential spillover effects to third countries resulting from discretionary fiscal policy in one country in a non-stochastic context. Some additional results are derived to test whether the exchange rate regime (flexible or fixed) matters for the size of the spillovers (relevant for EMU) and whether the type of policy (balanced-budget or debt-financed) matters (relevant for the Stability and Growth Pact and for the current debtfinanced tax cuts in the US). ${ }^{3}$ The choice of a fixed exchange rate over a flexible regime only seems to postpone the costs from the short to the long run, but the type of policy financing is crucial to determine if the external impact of a fiscal expansion by one country is positive or negative. The second part of the analysis reviews the assessments made so far of the potential gains from pursuing non-cooperative and cooperative fiscal stabilisation policies, in a stochastic environment. Even when large spillover effects are identified, coordination would only be useful if it can improve significantly upon nationally oriented policies There are still very few contributions addressing this question but, among these, Kim and Kim

\footnotetext{
${ }^{3}$ Here we compare a flexible exchange rate regime with a fixed exchange rate regime. This would address the question of whether coordination among EU countries could be more important than coordination among two countries with an independent floating regime, e.g. the US and the UK. Caselli (2001) instead compares an asymmetric peg (such as the hard Exchange Rate Mechanism) with a symmetric peg (such as monetary union).
} 
(2003) already give evidence that the gains can be potentially large. As a final note, however, attention is drawn to the need to reflect on some fundamental questions that have emerged as research in this area progresses, mainly about how to model fiscal policy and how to think about the interactions between fiscal and monetary policy.

\section{The New Framework of Open Economy Macroeconomics}

The first main difference between the new models and the old Mundell-Fleming-Dornbush (MFD) analysis is their micro-founded nature. The demand for products and the supply of labour result from the maximization of consumers' preferences, while output supply and prices result from the maximisation of firms' profits. Short-run price rigidities are the main feature inherited from the MFD, but the output dynamics generated by this assumption are better justified by the presence of monopolistic producers and profit margins, which ensure that in the short-run output is determined by demand.

In addition money demand is also introduced with a microeconomic foundation, usually by introducing money in the utility function. ${ }^{4}$ The money demand equations that result from utility maximisation are substantially different from the money demand equation typically assumed in the MFD framework. In NOEM models that introduce money in the utility function, money demand is a function of disposable income, while in MFD models it appears as a function of gross income. This difference can generate different dynamics for output and the exchange rate.

To give an idea of the dynamics that can be generated in NOEM models, this section will present their key ingredients, outlining in more detail the particular assumptions of the Redux model. Different assumptions have been studied in the literature but mostly to analyse their impact on the transmission of money supply shocks. ${ }^{5}$ Hence it is useful to return to the Redux starting point to address fiscal interactions.

\footnotetext{
${ }^{4}$ Alternatively money could be introduced using Cash-in-Advance constraints. See Coutinho (2002) for an example of a NOEM model with such constraints.

${ }^{5}$ For more exhaustive surveys of the NOEM literature see Lane (2001) and Ganelli and Lane (2002).
} 


\subsection{Preferences}

In NOEM, the allocation of resources between consumption, work effort and assets is based on the maximisation of the utility of households. The functional form that has been typically adopted for the consumers' utility takes the form:

$$
W_{t}^{j}=\sum_{s=t}^{\infty} \beta^{s-t}\left[U\left(C_{s}^{j}\right)+H\left(\frac{M_{s}^{j}}{P_{s}}\right)-V\left(Y_{s}^{j}\right)\right]
$$

where $C$ is a consumption bundle, $M / P$ are real money holdings and $Y$ is output (linked to work effort through a production function). The form of the functions $U, H, V$ is an important choice, since results have been shown to differ, sometimes crucially, according to the specifications chosen. The most often used are constant elasticity functions:

$$
\begin{aligned}
U\left(C_{s}^{j}\right) & =\frac{\left(C_{s}^{j}\right)^{1-\rho}}{1-\rho} \\
H\left(\frac{M_{s}^{j}}{P_{s}}\right) & =\chi \frac{\left(\frac{M_{s}^{j}}{P_{s}}\right)^{1-\varepsilon}}{1-\varepsilon} \\
V\left(Y_{s}^{j}\right) & =K \frac{\left(Y_{s}^{j}\right)^{\nu}}{\nu}
\end{aligned}
$$

In the Redux model of Obstfeld and Rogoff $\rho=\varepsilon=1$, and $U$, and $H$ reduce to logarithmic functions. With these assumptions optimal money holdings are proportional to the nominal consumption. The disutility from work effort in the Redux takes the quadratic form with $\nu=2$. It assumes a disutility of labour of the form $-\phi L$, where $L$ is labour and $\phi$ a positive parameter, and a production function of the form $Y=A L^{\alpha}$, where $\alpha=1 / 2$ and $K=2 \phi / A^{1 / \alpha}$. The variable $A$ is labour productivity (a rise in $A$ is captured by a fall in $K)$.

In the Redux model consumption preferences are over a basket of product varieties $C(z)$ produced in the home and foreign country:

$$
C^{j}=\left[\int_{0}^{1} C(z)^{\frac{\sigma-1}{\sigma}} d z\right]^{\frac{\sigma}{\sigma-1}}
$$

where $\sigma>1$. In this case the elasticity of substitution between home and foreign goods and the index of monopolistic distortion are implicitly the same. Corsetti and Pesenti 
(2001) separate the elasticity of substitution between home and foreign products using a Cobb-Douglas function to aggregate home goods and foreign goods into a total consumption basket. This implies a unitary elasticity of substitution between home and foreign goods, while the elasticity of substitution between varieties of each good remains equal to $\sigma$. In Corsetti and Pesenti's specification the unitary elasticity of intratemporal substitution is equal to the elasticity of relative net output demand with respect to relative prices. Therefore, when the relative price of the home good decreases, demand for that good increases relatively to the foreign good. Home income increases relative to foreign income but home purchasing power declines proportionally; therefore there is no incentive for international lending or borrowing: terms-of-trade movements provide complete risk sharing. In the Redux model however, the elasticity of substitution is bigger than one, hence home income increases relative to foreign income by more than the decline in the terms of trade and home residents are willing to lend resources abroad for consumption smoothing purposes. Although Corsetti and Pesenti's formulation shuts down the current account channel, it allows us to obtain analytical solutions without recourse to loglinearisations even without imposing symmetry across countries, so that the impact of structural differences across countries can be easily analysed. However, Tille (2001) shows that the assumption of a unitary elasticity of substitution between home and foreign goods may be too restrictive. He uses a model where the overall consumption basket is a CES aggregate of the home and foreign goods baskets, $C_{H}$ and $C_{F}$ respectively:

$$
C^{j}=\left[n^{\frac{1}{\theta}}\left(C_{H}^{j}\right)^{\frac{\theta-1}{\theta}}+(1-n)^{\frac{1}{\theta}}\left(C_{F}^{j}\right)^{\frac{\theta-1}{\theta}}\right]^{\frac{\theta}{\theta-1}}
$$

where $n$ is the relative size of country $H . C_{H}$ is a composite of goods produced at Home, aggregated with a constant elasticity $\sigma$, which also measures the degree of monopolistic competition within the country; and $C_{F}$ is a similar composite of goods produced in the foreign country. This specification encompasses the Redux when $\theta=\sigma$, and Corsetti and Pesenti (2001) when $\theta=1<\sigma$. The larger $\theta$, the larger the degree of substitutability between home and foreign goods, and the stronger the expenditure-switching effect caused by shocks to the economy. 


\subsection{Price Setting and Nominal Rigidities}

In the Redux model, prices are fixed simultaneously by all producers for one period. This implies that one period after the shocks the economy is again at steady-state. The assumption of simultaneous pricing decisions for all firms has been relaxed in subsequent models with Calvo or Taylor-type contracts. This allows us to generate persistency in the effects of shocks. ${ }^{6}$ The nominal rigidities can also take the form of pre-set wages, instead of pre-set prices. When firms face a constant elasticity of demand and therefore set prices as a constant mark-up over marginal costs, the wage stickiness fully translates into price-stickiness, hence pre-setting wages or prices result in the same transmission of shocks.

It is also assumed that there are no impediments to trade, so that the law of one price holds. Therefore, home's consumer price index corresponding to the consumption bundle (1) is given by:

$$
P=\left[\int_{0}^{n} P(h)^{1-\sigma} d h+\int_{n}^{1} \mathcal{E} P^{*}(f)^{1-\sigma} d f\right]^{\frac{1}{1-\sigma}}
$$

where $\mathcal{E}$ is the nominal exchange rate (domestic currency per unit of foreign currency). Since the foreign consumption bundle has the same composition as the domestic, it follows that purchasing power parity holds in this model, while the terms-of-trade $P(h) / \mathcal{E} P^{*}(f)$, defined as the ratio of the price of exports (price of goods produced domestically) to the price of imports (price of goods produced abroad), moves in response to shocks in the global economy. ${ }^{7}$

Another important assumption of the Redux regarding pricing and international trade is the assumption that prices are fixed in the exporters' currency. This has implications for how the terms-of-trade move in reaction to nominal exchange rate shocks. Under this assumption, the domestic terms-of-trade increase (improve), according to our definition,

\footnotetext{
${ }^{6}$ See Lane (2001) for a detailed discussion on this point.

${ }^{7}$ We maintain this definition throughout the paper. An increase in $P(h) / \mathcal{E} P^{*}(f)$ will be referred to as an improvement in the home country's terms of trade, since it implies that the home country receives relatively more for its exports while paying relatively less for its imports. The opposit is felt by foreign country, therefore an increase in $P(h) / \mathcal{E} P^{*}(f)$ corresponds to a worsening in the foreign country's terms of trade.
} 
when the domestic currency appreciates (when $\mathcal{E}$ falls), while the opposite would occur if prices where rigid in the currency of the importer (local currency pricing). Many contributions have analysed the implications of considering local currency pricing or of intermediate degrees of pass-through (see Lane, 2001, for a survey), which boil down to eliminating or reducing the expenditure-switching effect of a nominal exchange rate change, through which a depreciation of the domestic currency will cause the relative price of domestic exports to fall and redirect world demand towards domestic products.

\subsection{Budget Constraints}

The literature has considered both asset market completeness and incompleteness. With asset market completeness and the law of one price, there is complete risk sharing between countries and no shifts in wealth arising from exogenous shocks. This assumption eliminates the current account as a channel of transmission. It is important to note that the nature of asset markets is irrelevant in the set up of Corsetti and Pesenti (2001), since the unitary elasticity of substitution between home and foreign goods already ensures complete risk sharing. In the Redux model, in which elasticity of substitution between home and foreign goods is larger than one, financial markets are assumed to be incomplete with only one riskless bond being traded internationally, such that the individual $j$ 's budget constraint takes the form:

$$
P_{t} B_{t+1}^{j}+M_{t}^{j}=P_{t}\left(1+r_{t}\right) B_{t}^{j}+M_{t-1}^{j}+P_{t}(j) Y_{t}(j)-P_{t} C_{t}^{j}-P_{t} T_{t}
$$

where $M$ is money holdings, $B$ a one-period riskless bond and $T$ are net taxes.

As a mirror image of the consumer's budget constraint, the consolidated budget constraint of the fiscal and monetary authorities typically takes the form:

$$
0=T_{t}+\frac{M_{t}-M_{t-1}}{P_{t}}
$$

This constraint assumes no government spending. In section 3 the model will be extended to include fiscal policy. 


\subsection{Demand Curves, First Order Conditions and the Current Account}

Under the assumptions of the Redux, expenditure minimisation ensures that the demand of individual $j$ for product $z$ will take the form:

$$
C_{t}^{j}(z)=\left(\frac{P_{t}(z)}{P_{t}}\right)^{-\sigma} C_{t}^{j}
$$

With no home bias in private consumption the total demand faced by the producer of good $z$ is given by:

$$
Y_{t}^{d}(z)=\left(\frac{P_{t}(z)}{P_{t}}\right)^{-\sigma} C_{t}^{w}
$$

Given the demand curve faced by each producer, the maximisation of the representative consumer's utility subject to the budget constraint will define three main optimal relationships: the Euler equation, the money demand equation and the labour-leisure trade-off. Considering no heterogeneity between consumers within one country (therefore eliminating the superscripts $j$ ) these conditions in the Redux are the following for the home country:

$$
\begin{aligned}
C_{t+1} & =\beta\left(1+r_{t+1}\right) C_{t} \\
\frac{M_{t}}{P_{t}} & =\chi C_{t}\left(\frac{1+i_{t+1}}{i_{t+1}}\right) \\
Y_{t}^{\frac{\sigma+1}{\sigma}} & =\frac{\sigma-1}{\sigma k}\left(C_{t}^{w}\right)^{\frac{1}{\sigma}} \frac{1}{C_{t}}
\end{aligned}
$$

The conditions for the foreign country are parallel to this, with foreign variables indexed by an asterisk. Consolidating the consumer's budget constraint with that of the authorities gives the current account relationship. In the Redux, the current account relationship for the home country takes the following form (a parallel condition holds for the foreign country):

$$
B_{t+1}-B_{t}=r_{t} B_{t}+\frac{P_{t}(h) Y_{t}}{P_{t}}-C_{t}
$$

\subsection{Symmetric Steady State and Log-linearised Equations}

The Redux although relatively simple, does not have a closed-form solution. An approximate solution can be found by log-linearising the equilibrium conditions around the steady 
state. The initial symmetric steady state in the Redux is characterised by the following conditions:

$$
\begin{gathered}
\overline{\mathrm{r}}=\delta=\frac{1-\beta}{\beta} ; \quad \frac{\bar{P}_{0}(h)}{\bar{P}_{0}}=\frac{\bar{P}_{0}^{*}(f)}{\bar{P}_{0}^{*}}=1 \\
\bar{Y}_{0}=\bar{Y}_{0}^{*}=\bar{C}_{0}=\bar{C}_{0}^{*}=\bar{C}_{0}^{w}=\left(\frac{\sigma-1}{\sigma k}\right)^{\frac{1}{2}}
\end{gathered}
$$

The model can then be linearised around this steady state.

\subsection{The Short-run Equilibrium}

Since prices take only one period to adjust, the model is reduced to two periods: the short run, when prices remain fixed, and the long run, after adjustments take place. For this reason it is possible to drop the time subscripts and distinguish long-run variables with an upper bar. The labour-leisure trade-off is not binding in the short run and output is demand determined. ${ }^{8}$ Using the optimality condition for the money market it is possible to define an equilibrium locus between the exchange rate and relative consumption, which is downward sloping. An upward-sloping schedule between these two variables is found using optimality conditions other than the money market (and the labour-leisure trade-off).

With symmetric parameters, it is useful to resort to the Aoki method: differences between the equilibrium equations allow us to obtain the impact on relative variables (e.g. home output minus foreign output), while the sum of equilibrium equations allows us to obtain the results for the world aggregates $x^{w}=n x+(1-n) x^{*}$, where $n$ is the relative size of the home country and $x$ is any variable of interest (expressed in percentage deviation from its steady state value). The overall effects on $x$ and $x^{*}$ can then be obtained by combining the relative and aggregate effects, such that $x=x^{w}+(1-n)\left(x-x^{*}\right)$, and $x^{*}=x^{w}+-n\left(x-x^{*}\right)$.

\footnotetext{
${ }^{8}$ Corsetti and Pesenti (2001) note that the shock cannot be as large as to drive marginal costs above prices. In this case the monopolist would not keep prices constant. Hence the analysis applies only to a specific range of shocks.
} 


\subsection{The Long-run Equilibrium}

In the long run, the labour-leisure trade-off is binding. It defines an equilibrium schedule between long-run relative consumption and net foreign assets. The long and short-run current account conditions pin down net foreign assets in terms of shocks.

\subsection{Welfare Analysis}

The welfare effect of marginal shocks can be assessed by log-linearising the utility function. In the case of the Redux this yields:

$$
d U^{R}=c-\left(k \bar{y}_{0}^{2}\right) y+\frac{1}{\delta}\left(\bar{c}-\left(k \bar{y}_{0}^{2}\right) \bar{y}\right)
$$

where $U^{R}$ is the consumer's utility excluding the utility from holding money balances. This log-linearisation cannot be used to assess the impact of large shocks. One of the advantages of the model by Corsetti and Pesenti (2001) over the Redux is the fact that it has closed form solutions, allowing us to study the welfare effects without resorting to log-linearisation, which enables one to consider large shocks. ${ }^{9}$

\section{$3 \quad$ Fiscal Policy in the NOEM framework}

\subsection{Redux}

In Obstfeld and Rogoff's (1996) extension of the Redux model, government spending is introduced as a basket of public consumption goods aggregated in the same way as for private consumption, such that there is no home bias in government spending:

$$
G=\left[\int_{0}^{1} g(z)^{\frac{\sigma}{\sigma-1}} d z\right], G^{*}=\left[\int_{0}^{1} g^{*}(z)^{\frac{\sigma}{\sigma-1}} d z\right]
$$

The demand schedule for each public consumption good is given by:

$$
G(z)=\left[\frac{P(z)}{P}\right]^{-\sigma} G
$$

\footnotetext{
${ }^{9}$ Within the limits of the firms' and/or workers' participation constraints (see Corsetti and Pesenti, 2001).
} 
Government spending enters as an exogenous shock to the demand schedule of every producer:

$$
Y^{d}(z)=\left[\frac{P(z)}{P}\right]^{-\sigma}\left(C^{w}+G^{w}\right)
$$

The consolidated budget constraint of the fiscal and monetary authorities is also extended to consider government consumption:

$$
G=T+\frac{M-M_{0}}{P}
$$

The other building blocks of the model and steady state conditions remain the same as in the previous section. Log-linearising the model around a symmetric steady state, assuming that initial asset holdings are equal to zero, yields the following system of linear equations:

$$
\begin{array}{ll}
y_{t}=\sigma\left[p_{t}-p_{t}(h)\right]+c_{t}^{w}+g_{t}^{w} & \text { market clearing } \\
y_{t}^{*}=\sigma\left[p_{t}^{*}-p_{t}^{*}(f)\right]+c_{t}^{w}+g_{t}^{w} & \\
m_{t}-p_{t}=c_{t}-\frac{r}{1+\delta}-\frac{\bar{p}_{t}-p_{t}}{\delta} & \text { money demand } \\
m_{t}^{*}-p_{t}^{*}=c_{t}^{*}-\frac{r}{1+\delta}-\frac{\bar{p}_{t}^{*}-p_{t}^{*}}{\delta} & \\
(1+\sigma) y_{t}=-\sigma c_{t}+c_{t}^{w}+g_{t}^{w} & \text { labour-leisure trade-off } \\
(1+\sigma) y_{t}^{*}=-\sigma c_{t}^{*}+c_{t}^{w}+g_{t}^{w} & \\
\bar{b}=y-c-g-(1-n) e & \\
\bar{b}^{*}=y^{*}-c^{*}-g^{*}+n e & \\
\bar{c}=\delta \bar{b}+\bar{p}(h)+\bar{y}-\bar{p}-\bar{g} & \\
\bar{c}^{*}=\delta \bar{b}^{*}+\bar{p}^{*}(f)+\bar{y}^{*}-\bar{p}^{*}-\bar{g}^{*} &
\end{array}
$$

where lower case letters denote percentage deviations of upper case variables from their initial steady state values. ${ }^{10}$

With no home bias in government consumption, a balanced-budget increase in government spending increases demand for both domestic and foreign goods while the tax bill

\footnotetext{
${ }^{10}$ The algebra needed to derive these equations is described in detail in Obstfeld and Rogoff (1996).
} 
falls on domestic residents. A rise in home government spending increases world output. At home, however, the rise in output is not enough to offset the rise in taxes at home; therefore home consumption falls. Lower consumption implies lower money demand requiring a depreciation of the currency when prices are fixed. This raises demand for domestic goods and lowers demand for foreign goods, further rising output in the home country and dampening it abroad. When the domestic fiscal expansion is temporary, the net effect on foreign output in the short run is positive, because the direct effect of an increase in world demand is stronger than the negative effect caused by the depreciation of the home currency. However, when the domestic fiscal expansion is permanent, the negative effect of the depreciation dominates and the overall impact on foreign output is negative in the short run. This spillover effect is at odds with the predictions from MFD models. In the MFD models a fiscal expansion by one country leads to an appreciation of its currency and an increase for the demand of foreign products.

If the domestic fiscal expansion is temporary, the home country runs a deficit as in the standard flexible price intertemporal model. There is a fall in the long-run relative price of home goods and long-run relative output increases, while relative consumption goes down with the decrease in net foreign assets. In this case, the expansion reduces foreign output in the long run because in the long run there is no exogenous expansion of world demand (since the shock is temporary), but only a negative impact caused by the re-direction of world demand towards home goods (which became cheaper). Table 1 summarises the effects of a temporary fiscal expansion (see Appendix A.1 for details on these and other results presented in this section, most of which are also outlined in Obstfeld and Rogoff, 1996).

On the other hand, when the domestic expansion is permanent, the home country runs a surplus. With a permanent shock, the short-run nominal exchange rate depreciates by more and the positive impact of the depreciation on net foreign assets due to an increase in disposable income becomes larger than the negative impact of the increase in public consumption. ${ }^{11}$ In the long run there is still a decline in the relative price of home goods because

\footnotetext{
${ }^{11}$ Ganelli and Lane (2002) point out that this holds when the elasticity of intertemporal substitution of
} 
Table 1: Effects of a temporary balanced-budget increase in government spending in the Redux model

$$
\begin{aligned}
\frac{\partial c}{\partial g} & =-\frac{(1-n) \delta(1+\sigma)}{\sigma \delta(1+\sigma)+2 \sigma}<0 & \frac{\partial c}{\partial g^{*}} & =\frac{(1-n) \delta(1+\sigma)}{\sigma \delta(1+\sigma)+2 \sigma}>0 \\
\frac{\partial \bar{c}}{\partial g} & =-\frac{(1-n) \delta(1+\sigma)}{\sigma \delta(1+\sigma)+2 \sigma}<0 & \frac{\partial \bar{c}}{\partial g^{*}} & =\frac{(1-n) \delta(1+\sigma)}{\sigma \delta(1+\sigma)+2 \sigma}>0 \\
\frac{\partial y}{\partial g} & =n+\frac{\delta(1+\sigma)(1-n)}{\delta(1+\sigma)+2}>0 & \frac{\partial y}{\partial g^{*}} & =1-n-\frac{\delta(1+\sigma)(1-n)}{\delta(1+\sigma)+2}>0 \\
\frac{\partial \bar{y}}{\partial g} & =\frac{\delta(1-n)}{\delta(1+\sigma)+2}>0 & \frac{\partial \bar{y}}{\partial g^{*}} & =-\frac{\delta(1-n)}{\delta(1+\sigma)+2}<0
\end{aligned}
$$

the upward pressure on relative prices due to the increase in net foreign assets is more than offset by the downward pressure caused by the increase in long-run public consumption. The permanent fiscal expansion decreases long-run domestic private consumption at home and increases it abroad. Long-run income increases both at home and abroad. In this case the long-run spillover effect on foreign output is positive because there is a positive direct effect caused by the increase in world demand due to the fiscal expansion that offsets the negative impact caused by the decline in the relative price of home goods (which shifts demand away from foreign goods). ${ }^{12}$

Considering marginal changes in government spending, it is possible to evaluate the overall impact using the log-linearisation of consumer's utility function:

$$
d U^{R}=-\frac{\sigma-n}{2 \sigma}\left[2 g+\frac{(2 \sigma-n)}{(\sigma-n) \delta} \bar{g}\right]+\frac{(1-n)}{2 \sigma}\left[2 g^{*}+\frac{1}{\delta} \bar{g}^{*}\right]
$$

Overall, a domestic balanced-budget fiscal expansion (temporary or permanent) decreases welfare at home and increases it abroad. The reverse is true for a balanced-budget tax cut (fiscal contraction).

real money balances is smaller than $1+\theta$, which is the case with the Redux logarithmic preferences for real balances. With fixed prices, an unanticipated permanent increase in government spending tilts the time profile of output, since output rises more in the short-run than in the long-run on account of the temporary nominal rigidity, leading to a fall in the short-run real interest rate.

${ }^{12}$ The effects of a permanent fiscal expansion are shown in the Appendix A.1, and correspond to the results found in Ganelli (2003) for the case where fiscal spending does not enter the utility function (the case of $\gamma=0$ in his model). 
The beggar-thyself nature of a fiscal expansion in the Redux can be moderated by having government spending entering directly in the utility function. Ganelli(2003a) shows that with utility-enhancing government spending a domestic fiscal expansion can have a positive effect on welfare if the direct effect in utility more than offsets the negative welfare effects due to the crowding out of private consumption.

\subsection{Fixed-Exchange Rate Redux}

Maintaining the assumption of no-home bias in government consumption, a balanced-budget increase in government spending increases demand for both domestic and foreign goods. In the short run home and foreign output increase by the same amount through this effect. At home, the rise in output still cannot offset the rise in taxes; and therefore home consumption falls. Lower consumption implies lower money demand requiring a depreciation of the currency when prices are fixed. This time the exchange rate cannot change, hence money supply has to accommodate the change in relative consumption. With no change in the nominal exchange rate, there are no further effects on output: relative output does not change.

Under a fixed exchange rate, independently of whether the fiscal expansion is permanent or temporary, the overall effect on total relative consumption (private plus public) is positive. Since relative output does not change, net foreign assets decrease in the home country. Longrun relative consumption decreases and the long-run relative price of home goods declines. The fall in the relative price of home goods leads to an increase in relative output in the long run. This relative price change is stronger than in the case of a flexible exchange rate regime. Table 2 summarises these results. Interestingly, the overall effect of a fiscal expansion on welfare is the same under a flexible or a fixed exchange rate regime (see Appendix A.2 for details). The lower decrease in leisure in the short run under the fixed regime exactly offsets the larger negative impact on short and long-run consumption and on long-run leisure.

It is important to note that the assumptions regarding monetary policy are important to determine the results, since monetary policy will determine the response of short-run 
Table 2: Effects of a balanced-budget increase in government spending in a fixed-exchange rate Redux model

$$
\begin{aligned}
-\left.\frac{\partial\left(c-c^{*}\right)}{\partial\left(g-g^{*}\right)}\right|_{f i x} & =\frac{\delta(1+\sigma)}{\delta(1+\sigma)+2 \sigma}>-\left.\frac{\partial\left(c-c^{*}\right)}{\partial\left(g-g^{*}\right)}\right|_{f l e x}=\frac{\delta(1+\sigma)}{\sigma \delta(1+\sigma)+2 \sigma} \\
& \left.\frac{\partial\left(y-y^{*}\right)}{\partial\left(g-g^{*}\right)}\right|_{f i x}=0 \quad<\left.\frac{\partial\left(y-y^{*}\right)}{\partial\left(g-g^{*}\right)}\right|_{\text {flex }}=\frac{\delta(1+\sigma)}{\delta(1+\sigma)+2} \\
-\left.\frac{\partial\left(\bar{c}-\bar{c}^{*}\right)}{\partial\left(g-g^{*}\right)}\right|_{\text {fix }} & =\frac{\delta(1+\sigma)}{\delta(1+\sigma)+2 \sigma}>-\left.\frac{\partial\left(c-c^{*}\right)}{\partial\left(g-g^{*}\right)}\right|_{\text {flex }}=\frac{\delta(1+\sigma)}{\sigma \delta(1+\sigma)+2 \sigma} \\
\left.\frac{\partial\left(\bar{y}-\bar{y}^{*}\right)}{\partial\left(g-g^{*}\right)}\right|_{f i x} & =\frac{\delta \sigma}{\delta(1+\sigma)+2 \sigma}>\left.\frac{\partial\left(\bar{y}-\bar{y}^{*}\right)}{\partial\left(g-g^{*}\right)}\right|_{\text {flex }}=\frac{\delta}{\delta(1+\sigma)+2}
\end{aligned}
$$

aggregate consumption. Here we assume that in the two regimes the world money supply remains fixed. Caselli (2001) instead compares an asymmetric peg (such as the hard Exchange Rate Mechanism), where the world money supply has to change in response to shocks because only one country adjusts to keep the exchange rate fixed, with an symmetric peg (such as monetary union), where the world money supply is kept constant.

\subsection{Perfect Risk Sharing}

Betts and Devereux (1999) extended the Redux model to include complete asset markets, while keeping the assumption of no home bias in government spending, and found that in this case the costs of a fiscal expansion were shared equally by the two countries. As mentioned earlier, Corsetti and Pesenti (2001) develop a model where the degree of monopolistic competition and the elasticity of substitution between home and foreign goods are not equal as in the Redux. In their model the elasticity of substitution between home and foreign goods in the consumption bundle is one (due to the Cobb-Douglas aggregation), while the elasticity of substitution between varieties is bigger than one. In this formulation, the terms of trade provide the same kind of risk sharing as with complete markets. However, their results are not directly comparable to those of Betts and Devereux (1999) because they assume home bias in government spending. The implications of this assumption are discussed in the next section. 


\subsection{Home Bias and Consumption Substitutability}

Corsetti and Pesenti (2001) consider the other extreme case of complete home bias in government spending. In the short run, a domestic fiscal expansion raises domestic output one to one. Due to the Cobb-Douglas aggregation there are no effects on other variables. All the costs of a temporary fiscal expansion are borne by the expanding country. If the fiscal expansion is permanent, the increase in the demand for home goods caused by the increase in public consumption requires an upward adjustment in the relative price of home goods in the long run, leading to an improvement in home's terms-of-trade, defined here as the ratio of the price of goods produced at home to the price of goods produced abroad (the opposite occurs in the Redux where public spending falls equally on home and foreign goods). The longrun effects will ultimately depend on the degree of consumption substitutability between home and foreign goods. In Corsetti and Pesenti's (2001) model the degree of consumption substitutability between home and foreign goods is determined by the coefficient of risk aversion $\rho$, given that the elasticity of substitution between home and foreign goods in the consumption bundle is set to one by the Cobb-Douglas aggregation. If home and foreign goods are substitutes $(\rho>1)$, the effect of a domestic fiscal expansion on welfare abroad is always negative: a fiscal expansion increases the relative price of home goods reducing demand for the home good, if the goods are substitutes demand for the foreign good increases and so does labour supply, while foreign consumption decreases due to the negative impact on wealth due to the deterioration of the foreign country's terms of trade. If home and foreign goods are complements $(\rho<1)$, labour supply abroad decreases and the final effect depends on the relative weight of consumption and leisure in the utility, but Corsetti and Pesenti argue that the effect is negative for a wide range of parameter values.

Tille (2001) adopts a more general specification where the within-country elasticity of substitution $\sigma$, the cross-country elasticity of substitution $\theta$ and the coefficient of risk aversion $\rho$ are allowed to vary independently (the indexes assumed for the aggregation of goods were described in section 2.1. ${ }^{13}$ This specification encompasses the Redux when $\rho=1<\sigma=\theta$, and Corsetti and Pesenti (2001), when $\theta=1<\sigma$. As in Corsetti and

\footnotetext{
${ }^{13}$ The elasticity $\sigma$ has to be between 1 and $+\infty$ to ensure stability, but $\theta$ can be bigger or smaller than
} 
Pesenti (2001), the results differ from the Redux, not only because complete home bias in government expenditure is assumed, but also, and more importantly, because cross-country substitutability is going to determine the strength of the expenditure-switching effect of shocks. Assuming that $\rho=1$ for simplicity, when $\theta>1$, goods produced in different countries are close substitutes, and the Marshal-Lerner-Robinson (MLR) is satisfied. In this case, a fiscal expansion causes the net present value of revenues to fall (because substitution towards foreign goods caused by an increase in the relative price of home goods in the long run offsets the long-run improvement in home's terms-of-trade), while the opposite is true when $\theta<1 .{ }^{14}$ If government spending enters the utility of consumers, then home consumers will be better off in welfare terms following a domestic fiscal expansion, but this effect will be lower the higher the elasticity of substitution between home and foreign goods. For this reason, when direct utility from government expenditure is omitted, the welfare impact of a domestic fiscal expansion can be negative when the substitutability between home and foreign goods is high (beggar-thyself effect). Tille finds that the foreign country is always negatively affected by a domestic fiscal expansion, regardless of the assumptions concerning the utility of government spending. This beggar-thy-neighbour effect is stronger the lower the degree of cross-country substitutability, because with low substitutability, the deterioration of the foreign country's terms-of-trade is not compensated by a significant shift in demand towards foreign goods.

\subsection{Government Debt}

In the previous models Ricardian equivalence holds, therefore there is no role for government debt. In these models only balanced-budget fiscal policies can be analysed. One way one. It is also assumed that $\theta \rho>\rho-1$. The letters for the parameters follow the notation adopted in this paper, which is different from the one adopted in Tille (2001), where $1 / \sigma$ is our $\rho, \rho$ is our $\theta$, and $\theta$ is our $\sigma$.

${ }^{14}$ In the case of high substitutability between home and foreign goods $(\theta<1)$ there is a depreciation of the home currency in the short-run (like in the Redux) but the terms of trade improve in the long-run. In the case of low substitutability $(\theta<1)$ the terms of trade improve both in the long and in the short-run. In both cases the long-run effect dominates. In Corsetti and Pesenti's (2001) case of $\theta=1$, the short-term impact on the terms of trade is zero. 
to break down the Ricardian equivalence is to consider overlapping generations. Ganelli (2003b) uses an overlapping generations model to evaluate the effects of a debt-financed temporary reduction in taxes (long-run taxes increase endogenously in subsequent periods to meet the interest payments). He also outlines the effects of an increase in government expenditure financed by a tax increase (balanced budget) or by an increase in debt.

In Ganelli's Blanchard-type overlapping generations framework agents have a positive probability $(1-q)$ of dying and hence of not having to repay debt in the future. Therefore a debt-financed tax cut represents an increase in their net wealth. While a balanced-budget fiscal expansion by the home country in this model also produces a depreciation of the home currency (as in the Redux model), a debt-financed tax cut produces an appreciation of the domestic currency in the short run. This occurs because the increase in the net wealth of home consumers leads them to increase short-run consumption (the benefits for home agents are strong enough to compensate for the fact that there is a positive probability that they may be alive to repay the debt next period). Since the increase in consumption falls both on home and foreign products, profit shares increase at home and abroad leading to a further increase in consumption both at home and abroad. The increase of home consumption is greater than the increase in foreign consumption, hence domestic money demand increases relative to foreign demand, leading to the appreciation of the home currency. Analytically, the short-run effects of debt-financed tax cuts on consumption and on the exchange rate can be summarised as follows: ${ }^{15}$

$$
\begin{aligned}
\left(c-c^{*}\right) & =\frac{a_{4} a_{1}}{a_{2}(1+\psi)}\left(\frac{R_{0}-1}{R_{0}}+\frac{a_{3}}{(\sigma-1)}\right)\left(\bar{d}-\bar{d}^{*}\right) \\
e & =-\frac{a_{4} a_{1} \psi\left(R_{0}-1\right)}{a_{2}(1+\psi)(\sigma-1+\psi) R_{0}}\left(\bar{d}-\bar{d}^{*}\right) \\
c^{w} & =\frac{a_{5}}{(1+\psi) q R_{0}} \bar{d}^{w}
\end{aligned}
$$

where $a_{1}, a_{2}, a_{3}, a_{4}$ and $a_{5}$ are positive coefficients, $\psi$ is the weight of the disutility of labour in the utility function, $q$ is the probability of surviving, $R_{0}$ is the steady-state gross real rate

\footnotetext{
${ }^{15}$ The results for short-run relative consumption and output can be found in Ganelli (2003b). The results for the log-linear world aggregates are derived in the Appendix.
} 
of interest and $\bar{d}$ is the increase in debt required to finance the tax cut. ${ }^{16}$ Since short-run world consumption and relative consumption both increase following a debt-financed tax cut by the home country, the overall impact of this policy on short-run home consumption is positive. The effect on short-run foreign consumption, however, depends on whether the increase in world demand is enough to compensate for the decline in the foreign country's terms-of-trade. Carrying out simulations for a range of reasonable parameter values suggests that the effect is likely to be positive (the simulations and baseline parameters are explained in Appendix A.3).

The short-run appreciation of the home currency leads to a decline in relative output (in the short run output is determined by demand and is not influenced by supply-side labourleisure trade-off decisions). However, since world output increases due to the increase in consumption both at home and abroad, the overall effect on domestic output is ambiguous, but the negative effect caused by expenditure-switching is smaller the larger the size of the country. Overall, the simulations show that the effect is most probably positive. The output spillover effect on the foreign country is always positive regardless of the size of the country. Analytically, these are the short-run effects on output:

$$
\begin{aligned}
\left(y-y^{*}\right) & =\sigma e=e=-\frac{a_{4} a_{1} \psi \sigma\left(R_{0}-1\right)}{a_{2}(1+\psi)(\sigma-1+\psi) R_{0}}\left(\bar{d}-\bar{d}^{*}\right) \\
y^{w} & =\frac{a_{5}}{(1+\psi) q R_{0}} \bar{d}^{w}
\end{aligned}
$$

The simulations (see Appendix for details) also show that the short-run impact on welfare is likely to be positive for the home country and negative abroad. The effects decline as the probability of staying alive next period, $q$, increases. The spillover welfare effects on the foreign country only appear to be positive when the home country is small (less than 0.3 of the world market for the baseline simulation values) or when the elasticity of substitution

\footnotetext{
${ }^{16}$ The expressions for the coefficients $a_{i}$ in terms of the structural parameters are:

$a_{1}=\frac{1-q \beta}{1+\chi+\psi}(1-q)(1+\psi) \frac{R_{0}}{R_{0}-q}$

$a_{2}=1-a_{1} \frac{\psi^{2}}{(\sigma-1+\psi)(1+\psi)}$

$a_{3}=\frac{\sigma-1+\sigma \psi}{\sigma-1+\psi}$

$a_{4}=\frac{a_{2} R_{0}\left(R_{0}-1\right)(\sigma-1)}{q \beta\left(a_{3} R_{0}+(\sigma-1)\left(R_{0}-1\right)\right)+\left(R_{0}-1\right)\left(a_{2} R_{0}+(\sigma-1)\left(R_{0}-1\right)\right)}$

$a_{5}=\frac{a_{1}\left(R_{0}-q\right) R_{0}}{\beta\left(R_{0}-q\right) R_{0}-a_{1}}$
} 
between varieties is low (for this result, the elasticity of substitution should be less than 4.5, while the literature, e.g. Rottemberg and Woodford (1998), usually calibrates this parameter above 7). Figures 1,2 and 3 show the sensitivity of the simulations to these parameters.

To assess the long-run impact of the tax cut financed by debt, it is sufficient to observe that net foreign assets decrease and the country runs a deficit. Long-run relative consumption decreases and the long-run relative price of home goods falls, leading also to an increase in relative output. Hence, in the long run this policy has detrimental effects for the welfare in the home country and positive effects for the foreign country. ${ }^{17}$ The overall assessment of the policy depends on the relative weight with which the fiscal authorities value the welfare of current and future generations. Simulations suggest that the short-run impact is likely to dominate, and therefore a debt-financed tax cut is likely to be beggar-thy-neighbour. However, reasonable parameter values in this model do not seem to produce spillover effects above $0.02 \%$ for an increase in debt of $1 \%$ (percentages of steady state output). This finding that spillovers are small would concur with simulations carried out with several general equilibrium macroeconomic models (see Gros and Hobza, 2001). But it is important to notice that the model is a non-stochastic model with many simplifying assumptions that could be relaxed. The sign rather than the size of the effects should be taken as the main point of the exercise, which shows that including non-Ricardian elements in the analysis can substantially alter the predictions of the Redux.

As pointed out by Ganelli (2003b), this model can partially explain the effects of the tax cut announced in 2001 by the US administration. According to the model, this announcement will have contributed to strengthen the dollar in that year. The model also predicts that, in the long run, the announcement should result in a depreciation of the US currency driven by a deterioration in net foreign assets. This is what happened following the tax cuts of the Reagan administration. This time however, the long run seems to have come

\footnotetext{
${ }^{17}$ Notice that in the long run the relative responses are enough to assess the overall impact on each variable, since long-run world consumption and output do not change when government spending is kept constant (for details see Appendix A.3).
} 
rather quickly, since the dollar started to fall against other major currencies immediately since the second quarter of 2002. However, this can be justified by the fact that the US is now the world's largest debtor and that, therefore, concerns about the sustainability of the US current account have set in much faster than before.

The effects of a debt-financed increase in government expenditure, assuming no home bias in public consumption, are outlined in Ganelli (2003b). This measure can be seen as the sum of a debt-financed tax cut and a balanced budget increase in government spending. In this case, the effects on the exchange rate are ambiguous. In the short run, the "debt" effect pushes for an appreciation, while the "balanced-budget" effect pushes for depreciation. Therefore, in this model, when countries are allowed to accumulate debt, fiscal expansions can be welfare improving for the home country. However, if countries are bound by rules limiting the size of the budget deficits, the country is more likely to benefit from fiscal contractions instead (balanced-budget tax-cuts), in the same way as in the Redux model.

\section{Fiscal Policy Coordination}

It is important to note that the identification of policy spillovers per se does not necessarily imply gains from policy coordination. Even when large spillover effects are identified, coordination would only be useful if it can bring welfare significantly above the level obtained by nationally oriented policies. The initial contributions to the still-emerging second generation of policy coordination models, namely Obstfeld and Rogoff (2002) and Corsetti and Pesenti (2001), which focus on monetary policy, could not produce substantial coordination gains. Canzoneri et al. (2002a) point out the fact that this is due to some simplifying assumptions which ensure analytical tractability but considerably reduce interdependence, making these models at the end as unlikely to produce large gains from coordination as the first-generation old-Keynesian models were. The simplifying assumption of a Cobb-Douglas aggregation for the consumption bundle, for instance, implies that expected employment is either insulated from shocks or is proportional to expected consumption. Therefore, there is no trade-off between the stabilisation of consumption and the stabilisation of employ- 
ment, which are the two objectives built into the social welfare function. ${ }^{18}$ In addition the assumption that shocks are symmetric across sectors excludes the possibility of additional trade-offs in the stabilisation of consumption that could stem from asymmetric sectoral shocks. Canzoneri et al. (2002a) show that even maintaining the restrictive assumptions that render the models tractable it is possible to obtain large gains with asymmetric sectoral shocks.

When no, or only insignificant, trade-offs are implied by the Nash solution, central banks can mimic or close to mimic the flexible price equilibrium, and since in that case the flexible price solution is equal or is close to the (constrained) optimum, the Nash and the Cooperative solutions coincide or are close to each other. This was one of the main reasons why the old models could only generate gains from achieving efficiency through cooperation that were of a second order when compared to the gains of responding to the shocks themselves (see Canzoneri and Minford, 1988). Apart from the price inertia, there were no other plausible distortions that could drive the cooperative and Nash solutions sufficiently apart.

In the NOEM literature, monopolistic competition is an additional source of inefficiency, but Obstfeld and Rogoff (2002) show that it must still be coupled with other distortions such as financial market frictions or distortionary taxes to generate first-order gains from cooperation. Otherwise, the cooperative solution will always target the flexible price equilibrium, which will also be a Nash solution. In their model, which is a stochastic version of the Redux where the intertemporal elasticity of substitution $\rho$ is allowed to be different from 1 , this occurs precisely when $\rho=1$ (the case of the Redux) or when all shocks are symmetric. Whenever these conditions are not met, the sharing of tradable consumption risks is not efficient and there is another distortion in addition to the one caused by monopoly. Hence the optimal cooperative policy will strike a balance between improving the risk sharing and mitigating the price rigidities. However, making $\rho$ differ from one in their model is

\footnotetext{
${ }^{18}$ Direct utility from money balances tends to be ignored to avoid dealing with the accompanying incentives for central banks to generate surprise inflation or deflation. Direct utility from government spending would create the additional objective of stabilisation of government expenditure.
} 
not sufficient to generate large gains. But following this direction, Sutherland (2002) shows that adopting a constant elasticity of substitution (CES) aggregation for the consumption bundle together with the assumption of financial market imperfections can generate such potentially large gains. ${ }^{19}$ However, this and other similar promising extensions to the Redux result in a welfare function that depends on the first as well as on the second moments of the variables. Since the first moments of the relevant variables depend also on the second moments, it becomes necessary to calculate the solution of a second-order approximation of the model to obtain an accurate measure of welfare (see Kim and Kim, 2002). This type of solution is more difficult to obtain and the necessary computational methods have only recently been applied to these problems. ${ }^{20}$

So far, the main focus of attention in this "second-generation" literature has been monetary policy coordination, probably because, as mentioned in the introduction, there are doubts about whether fiscal policy can be useful as a stabilisation tool, but also because very little is still known about the stylised facts of the transmission of fiscal policy which would enable one to choose between alternative specifications. Nevertheless, a few studies have begun to revisit the issue. Beetsa and Jensen (2002) include fiscal policy in a model similar to that of Obstfeld and Rogoff (2002) to analyse the gains from stabilisation using balanced-budget changes in government spending in a monetary union where the fiscal authorities commit to cooperate and therefore maximise the aggregate welfare of the union. By focusing only on the cooperative solution they avoid the problem of calculating first moments because in the cooperative solution these terms drop from the welfare function and a first-order solution to the model is enough to measure the changes in the joint utility. In their model consumers derive direct utility from fiscal expansions and there is complete

\footnotetext{
${ }^{19}$ Benigno (2001) had already shown that these two features increased welfare in the cooperative solution but, using a first order approximation to solve the model, could not estimate accurate Nash solutions in order to assess the net gains from coordination. Sutherland (2002) is able to estimate these gains with a second-order solution method.

${ }^{20}$ Alternative methods are proposed in Schmitt-Grohe and Uribe (2001) and in Sutherland (2002). Christopher Sims also proposes a different method for which the computational routines are available with notes at http://eco-072399b.princeton.edu/yftp/gensys2/
} 
home bias in government purchases. They show that the optimal fiscal policy will close the terms-of-trade gap between the two regions in the union. They also show that there are benefits of commitment over discretion, because under discretion fiscal policy is less active and less persistent towards stabilising shocks than under commitment resulting in a lower level of welfare. Finally the model is also used to calculate the gains from using public spending for macroeconomic stabilisation. In their benchmark calculation the gains amount to a permanent consumption gain of about $0.6 \%$ of steady-state output. However, to estimate the net gains from coordination it is necessary to obtain estimates of the levels of welfare when each individual country plays Nash. This requires a second-order accurate solution of the model.

Kim and Kim (2003) estimate gains from international tax policy cooperation using a second-order accurate solution method but in a rather different model. They use a cashless model where consumers derive utility from consumption and leisure in a non-separable way. They also introduce capital in the model and consider costs to capital accumulation. Their results show that in this model the optimal tax policies respond pro-cyclically to productivity shocks (positive productivity shocks prompt a reduction in taxes). They find gains from fiscal policy stabilisation of about $0.007 \%$ and $0.001 \%$ of output, depending on the type of policy analysed, and additional welfare gains from tax policy coordination relative to the Nash outcome of approximately $33 \%$. In their calibrations the coefficient of risk aversion is equal to 2 . Table 3 summarises their results.

Table 3: Gains from stabilisation and coordination using alternative tax policies under flexible exchange rates (percent of output).

\begin{tabular}{l|cc}
\hline & Capital Income Tax Policy & Labour Income Tax Policy \\
\hline (i) Stabilization gain & 0.0065 & 0.0015 \\
(ii) Coordination gain & 0.0022 & 0.0005 \\
(iii) Ratio 100x(ii)/(i) & 33.8462 & 33.3333 \\
\hline
\end{tabular}

Source: Kim and Kim (2003) 
As the research progresses in this area, many fundamental questions emerge about how to model fiscal policy and how to think about the interactions between fiscal and monetary policy. There are many doubts about how to think of fiscal policy in this literature. Canzoneri et al. (2002b) argue that discretionary changes in fiscal policy cannot be usefully modelled from the perspective of stabilisation policy, because of its implementation delays and its dependence on the political mood of the electorate. For this reason, they propose looking at fiscal shocks as additional disturbances to which the monetary authorities have to respond. An alternative way of thinking could be to focus on the best design of automatic stabilisers. So far the preferences have been towards modelling fiscal policy using simple rules. Beetsa and Jensen (2002) choose rules in which fiscal expenditure responds automatically to changes in the consumption and terms-of-trade gaps, while in Kim and Kim (2003) taxes respond in a pre-determined way to productivity shocks, much in the same way as monetary policy rules have been modelled in many studies. Could these rules be interpreted as an optimal design for fiscal stabilisers?

Another important issue is whether the models that are currently being used are adequate. This is a difficult question to answer since very little is still known about the stylised facts of fiscal policy transmission. Only recently vector auto-regressive (VAR) analysis has been used to study fiscal policy transmission channels empirically (see for instance Blanchard and Perotti, 2002). The results found so far in this analysis tend to predict a positive response of consumption to an increase in government spending which is easier to reconcile with the old MFD framework than with the Redux and many of its extensions. Canzoneri et al. (2002b) point out that models that consider deviations from Ricardian equivalence (e.g. finitely lived agents, borrowing constraints or other financial market imperfections) may be able to match better the stylised facts found with VAR analysis (these empirical estimates however are still very imprecise and should be taken with reservations). In the overlapping generations model described in section 3.5, a debt-financed fiscal expansion was in fact able to generate a wealth effect that led to an increase in consumption. Hence, from an empirical perspective it seems more plausible to proceed with the analysis of policy coordination using models of this type. Also from a practical view point, most fiscal policy 
actions are debt-financed rather than balanced-budget; hence it seems natural to use models which allow us to analyse debt-financed policies.

But another important point, the interaction between monetary and fiscal polices, has so far been essentially overlooked, mainly for the sake of simplicity. This however is also likely to be an important issue, since monetary policy determines how consumption ultimately responds in the short run. In the fixed exchange rate version of the Redux presented in section 3.2, the world money supply was kept constant, for instance. This determined that short-run aggregate consumption did not change. Also due to the effects of money growth on consumption, Caselli (2001) shows that the impact of fiscal consolidation depends on whether a fixed exchange rate regime is symmetric (e.g. European Monetary Union) or asymmetric (e.g. ERM). The choice of monetary regime and the way monetary and fiscal authorities interact is therefore likely to be crucial for welfare comparisons and hence deserves thorough consideration.

\section{Conclusions}

The main goals of this article were to review the analysis of fiscal policy within recent new open economy macroeconomic (NOEM) models, and to try to address a number of outstanding questions, while also pointing to some challenges for future research. The analysis focused on two points: firstly, on the identification of potential spillover effects to third countries resulting from an active fiscal policy in one country in a non-stochastic context; secondly, on the assessment of the potential gains from pursuing non-cooperative and cooperative fiscal stabilisation policies.

There has been relatively little research on fiscal policy in the NOEM literature, but nevertheless some important results can be highlighted concerning the impact of unantic-

ipated changes in fiscal policy at home and abroad. In the basic model, the Redux, a domestic balanced-budget fiscal expansion prompts a depreciation of the home currency's nominal exchange rate and a deterioration of the home country's terms of trade (defined 
as the ratio of the price of home goods to the price of foreign goods), which is at odds with the predictions of the traditional Mundell-Fleming-Dornbush (MFD) model where a fiscal expansion by one country leads to a appreciation of its currency. Moreover, in the Redux model, the negative impact of the deterioration in home's terms of trade both in the short run, when prices are fixed, and in the long run, dominates the expenditureswitching effect triggered by the fall in the relative price of the goods produced at home. Hence, in terms of its impact on welfare, the domestic fiscal expansion is beggar-thyself and prosper-thy-neighbour. Households in the home country are worse off because they work more and consume less (their income is lower due both to the increase in taxes needed to finance the fiscal expansion and to a decline in sale's revenues), while foreign households work relatively less and consume more. In order to understand whether the exchange rate regime is important to determine the results, we re-estimate the effects of a domestic fiscal expansion in a fixed exchange rate version of the model. It turns out that the estimated impact on the intertemporal welfare of consumers is the same under flexible or fixed rates (keeping the world money stock constant under both regimes). Under fixed exchange rates, the costs/benefits of fiscal policy are simply postponed from the short to the long run. In the case of the home country, for instance, the short-run costs of the fiscal expansion are smaller because there is no adjustment in the terms of trade (since prices are sticky and the nominal exchange rate is not allowed to change). This however is counterbalanced by higher long-run costs, since in the long run the terms of trade decline by more than in the flexible exchange rate model, because the deterioration of the net foreign asset position is stronger under fixed exchange rates (as the decline in relative wealth due to the increase in taxation is not compensated by a short-run expenditure switching-effect towards home goods, which under flexible exchange rates is brought about by an exchange rate depreciation).

There are two main assumptions that seem to drive the effects a fiscal expansion in the Redux: $(i)$ the assumption of no home bias in fiscal spending; and (ii) the assumption that the degree of within-country substitutability (substitutability between the varieties of the good produced within the country), which must be bigger than one, is the same as the degree of cross-country substitutability (substitutability between the goods produced by 
the different countries). If $(i)$ does not hold, and there is instead home bias in government spending, it is no longer true that home households must split the direct benefits of an increase in demand with foreign households, while baring all the costs trough higher taxes. Hence, in net-present-value terms there is an improvement in the terms of trade of the home country, as opposed to the decline observed in the Redux. Assuming complete home bias in government spending can alter the beggar-thyself and prosper-thy-neighbour effects of a domestic fiscal expansion depending on the relationship between the within and the crosscountry substitutability. If the cross-country substitutability is sufficiently low the fiscal expansion will be prosper-thyself and beggar-thy-neighbour, because the improvement in the terms of trade of the home country will not be offset by a large shift in demand towards foreign goods. In this case foreign consumers will be worse off because the expenditureswitching effect will not be strong enough to compensate for the deterioration in the foreign country's terms of trade.

An alternative setup where a domestic fiscal expansion can prosper-thyself and beggarthy-neighbour is one where the Ricardian equivalence no longer holds and fiscal expansions are debt-financed. Using the overlapping generations model described in Ganelli (2003b) we show that, in most cases, a tax cut financed by debt at home will improve welfare at home and reduce it abroad. This occurs because, once more, the effect which is most likely to dominate is an increase in consumption at home and a decline abroad caused by a change in the terms of trade in favour of the home country. In the absence of Ricardian equivalence, a debt-financed fiscal expansion generates a wealth effect in the home country which prompts a short-run appreciation of the home currency, more in line with the predictions of the old MFD framework.

It is important to note that the identification of policy spillovers per se does not necessarily imply gains from policy coordination, because in some situations the authorities can reach a similar, or even identical, outcome acting independently or jointly. Research on monetary policy has shown that it is theoretically possible to generate large gains from coordination, but that has been achieved at the expense of analytical tractability. Regarding 
fiscal policy, Kim and Kim (2003) give already an example where the gains can be potentially large, but more research needs to be pursued to test the robustness of the results to other types of policy and model specifications. In particular, the estimation of coordination gains has so far been carried out using models where the Ricardian equivalence holds and where only balanced-budget policies can be analysed. Canzoneri et al. (2002b) point out that future research should focus on deviations from Ricardian equivalence, which could bring the fiscal policy transmission in the models more in line with stylised facts found so far in vector auto-regressive (VAR) analysis. In particular, the empirical finding that consumption increases in the short run in response to an increase in government spending is at odds with the theoretical predictions of the Redux and many of the extensions that have been used so far to quantify the gains from coordination. An overlapping generations model of the type described in section 3.5 would be able to generate this response, but has not yet been used to estimate coordination gains. These kind of models also have the advantage of allowing us to analyse debt-financed changes in fiscal policy, which are more often observed empirically than balanced-budget ones.

Finally, it has been pointed out that more thought should be put into how to interpret fiscal policy is these models. Should it be simply interpreted as an additional shock to which monetary policy should respond or can it be interpreted as a useful stabilisation tool? Can simple fiscal policy rules be used as a proxy for the design of optimal fiscal stabilisers? Another important issue that was highlighted as deserving particular attention is the interaction between fiscal and monetary policy, which has in most cases been overlooked, but seem to be important, at least from a theoretical perspective. 


\section{References}

[1] Beetsa, R. and Jensen, H., 2002, Monetary and Fiscal Policy Interactions in a MicroFunded Model of a Monetary Union, Centre for Economic Policy Research (CEPR) Discussion Paper 3591, October.

[2] Begnino, P., 2001, Price stability with imperfect financial integration, Centre For Economic Policy Research (CEPR) Discussion Paper No. 2854.

[3] Betts, C. and Devereux, M., 1999, The International Effects of Monetary and Fiscal Policy in a Two-Country Model, University of British Columbia Discussion Paper 9910, http://www.econ.ubc.ca/dp9910.pdf

[4] Blanchard, O., and Perotti, R., 2002, An Empirical Investigation of the Dynamic Effects of Shocks to Government Spending and Taxes on Output, Quarterly Journal of Economics (U.S.); 117, No. 4:1329-68, November. Previous version: http://www.iue.it/Personal/Perotti/papers/blanchardperotti4_02.pdf

[5] Canzoneri, M.B., Cumby, R.E., and Diba, B.T., 2002a, The Need for International Policy Coordination: What's Old, What's New and What's Yet to Come?, National Bureau of Economic Research (NBER) Working Paper 8765.

[6] Canzoneri, M.B., Cumby, R.E., and Diba, B.T., 2002b, New Views on the Transatlantic Transmission of Fiscal and Macroeconomic Policy Coordination, paper prepared for the European Commission Workshop on "The Interactions Between Fiscal and Monetary Policies in EMU", March 8, 2002, Brussels. http://www.georgetown.edu/faculty/canzonem/F\&M-Coordination.pdf

[7] Canzoneri, M. B., and Minford, P., 1988, When International Policy Coordination Matters: an Empirical Analysis, Applied Economics, 20, pp.1137-1154.

[8] Caselli, P., 2001, Fiscal Consolidation under fixed exchange rates, European Economic Review 45, pp.425-450. 
[9] Corsetti, G., and Pesenti, P., 2001, Welfare and Macroeconomic Interdependence, Quarterly Journal of Economics 116(2), May, pp.421-446.

[10] Coutinho, L., 2002, Monetary Policy Rules and the International Monetary Transmission, Centre for European Policy Studies (CEPS) Working Document No. 191, October. http://shop.ceps.be/free/101.pdf

[11] European Convention, 2003, New or revised provisions of Part III, 11 June. http://european-convention.eu.int/docs/Treaty/CV00805.EN03.pdf

[12] Ganelli, G., 2002, Fiscal Policy Rules in an Overlapping Generations Model with Endogenous Labour Supply, Trinity Economic Paper 15, 2002, http://econserv2.bess.tcd.ie/TEP/TEPNo15GG22.htm

[13] Ganelli, G., 2003a, Useful Government Spending, Direct Crowding-Out and Fiscal Policy Interdependence, Journal of International Money and Finance 22, pp.87-103.

[14] Ganelli, G., 2003b, The New Open Economy Macroeconomics of Government Debt, http://econserv2.bess.tcd.ie/ganellig/debt.pdf, previous version: Trinity Economic Paper No. 14, http://econserv2.bess.tcd.ie/TEP/TEPNo14GG22.pdf

[15] Ganelli, G. and Lane, P., 2002, Dynamic General Equilibrium Analysis: The Open Economy Dimension, CEPR Discussion Paper No. 3540.

[16] Gros, D., and, Hobza, A., 2001, Fiscal Policy Spillovers in the Euro Area: Where are they?, Centre for European Policy Studies (CEPS) Working Document No. 176.http://shop.ceps.be/free/86.pdf?

[17] Kim, J., and Kim, S.H., 2002, Spurious Welfare Reversals in International Business Cycle Models, www.people.virginia.edu/ jk9n/lw_com17.pdf, also forthcoming in Journal of International Economics.

[18] Kim, J., and Kim, S.H., 2003, Welfare Effects of International Tax Policy in Open Economies: Stabilization and Cooperation, mimeo, http://www.people.virginia.edu/ jk9n/tax11.pdf 
[19] Lane, P., 2001, The New Open Macroeconomics: A Survey, Journal of International Economics, 54(2), August, pp.235-266.

[20] Meyer, L.H., Doyle, B.M., Gagnon, J.E., Henderson, D.H., 2002, International Coordination of Macroeconomic Policies: Still Alive in the New Milenium?, Board of Governors of the Federal Reserve System, International Finance Discussion Paper 723, April, http://www.federalreserve.gov/pubs/ifdp/2002/723/ifdp723.pdf

[21] Obstfeld, M., and Rogoff, K., 1995, Exchange Rate Dynamics Redux, Journal of Political Economy 103, pp. 640-60.

[22] Obstfeld, M., and Rogoff, K., 1996, Foundations of International Macroeconomics, MIT Press, Cambridge, MA, Chapter 10.

[23] Obstfeld, M., and Rogoff, K., 2002, Global Implicatios of Self Oriented National Monetary Rules, Quarterly Journal of Economics 117, pp. 503-36.

[24] Rottemberg, J.J., and Woodford, M., 1998, An Optimization- Based Econometric Framework for the Evaluation of Monetary Policy, in B. S. Bernanke and Rottemberg (eds), NBER Macroeconomic Annual 1997, Cambridge, MA: MIT Press, pp. 297-346.

[25] Schmitt-Grohe, S., and Uribe, M., 2001, Solving Dynamic General Equilibrium Models Using a Second-Order Approximation to the Policy Function. Forthcoming Journal of Economic Dynamics and Control. Also http://papers.ssrn.com/sol3/delivery.cfm/SSRN_ID277709_code010803670.pdf?abstractid=277709.

[26] Sutherland, A., 2002, A Simple Second-Order Solution Method For Dynamic General Equilibrium Models, Centre For Economic Policy Research (CEPR). Discussion Paper No. 3552, September.

[27] Tille, C., 2001, The Role of Consumption Substitutability in the International Transmission of Shocks, Journal of International Economics, 53, April, pp.421-444. 


\section{A Appendix}

\section{A.1 Flexible Exchange Rate Redux}

The log-linear model is described by the system of equations presented in section 3 . Note that the market clearing ensures also that $y_{t}^{w}=c_{t}^{w}+g_{t}^{w}$ and $\left(-\frac{n}{1-n}\right) \bar{b}=\bar{b}^{*}$. From the Euler equation short-run money demand equations, it is also possible to write:

$$
\begin{aligned}
c^{w} & =\bar{c}^{w}-\frac{\delta}{1+\delta} r \\
m^{w} & =c^{w}-\frac{r}{1+\delta}-\frac{\bar{p}^{w}}{\delta}
\end{aligned}
$$

where from the long-run money demand equation $\bar{p}^{w}=\bar{m}^{w}-\bar{c}^{w}$. Hence:

$$
\begin{aligned}
r & =\frac{1+\delta}{\delta}\left(\bar{c}^{w}-\frac{\delta m^{w}+\bar{m}^{w}}{1+\delta}\right) \\
c^{w} & =\bar{c}^{w}-\left(\bar{c}^{w}-\frac{\delta m^{w}+\bar{m}^{w}}{1+\delta}\right)=\frac{\delta m^{w}+\bar{m}^{w}}{1+\delta}
\end{aligned}
$$

Monetary policy is crucial in determining the level of short-run aggregate demand but for simplicity we will assume that $m=m^{*}=m^{w}=\bar{m}=\bar{m}^{*}=\bar{m}^{w}=0$. Therefore:

$$
\begin{aligned}
r & =\frac{1+\delta}{\delta} \bar{c}^{w} \\
c^{w} & =0
\end{aligned}
$$

Note that this result depends on the assumption of log-preferences for real money balances, if the elasticity is $\varepsilon \neq 1$, short-run aggregate consumption will still be linked to the long-run aggregate consumption:

$$
\begin{aligned}
y^{w} & =c_{t}^{w}+g_{t}^{w}=g_{t}^{w} \\
\left(c-c^{*}\right) & =\left(\bar{c}-\bar{c}^{*}\right)=-e=-\frac{\delta(1+\sigma)}{\sigma \delta(1+\sigma)+2 \sigma}\left[\left(g-g^{*}\right)+\frac{1}{\delta}\left(\bar{g}-\bar{g}^{*}\right)\right] \\
\left(y-y^{*}\right) & =\sigma e=\frac{\delta(1+\sigma)}{\delta(1+\sigma)+2}\left[\left(g-g^{*}\right)+\frac{1}{\delta}\left(\bar{g}-\bar{g}^{*}\right)\right]
\end{aligned}
$$




$$
\begin{aligned}
\bar{b} & =\frac{(1-n) \delta(1+\sigma)}{\delta(1+\sigma)+2}\left[\left(g-g^{*}\right)+\frac{1}{\delta}\left(\bar{g}-\bar{g}^{*}\right)\right]-(1-n)\left(g-g^{*}\right) \\
\overline{t o t} & \equiv \bar{p}(h)-\bar{e}-\bar{p}^{*}(f)-=-\frac{\delta}{\sigma[\delta(1+\sigma)+2]}\left[\left(g-g^{*}\right)+\frac{1}{\delta}\left(\bar{g}-\bar{g}^{*}\right)\right] \\
\left(\bar{y}-\bar{y}^{*}\right) & =-\sigma \overline{t o t}=\frac{\delta}{\delta(1+\sigma)+2}\left[\left(g-g^{*}\right)+\frac{1}{\delta}\left(\bar{g}-\bar{g}^{*}\right)\right]
\end{aligned}
$$

where tot stands for home's terms of trade. Using the Aoki decomposition $c=c^{w}+(1-$ $n)\left(c-c^{*}\right)$ and $y=y^{w}+(1-n)\left(y-y^{*}\right)$, it is possible to obtain:

$$
\begin{aligned}
& c=-\frac{(1-n) \delta(1+\sigma)}{\sigma \delta(1+\sigma)+2 \sigma}\left[\left(g-g^{*}\right)+\frac{1}{\delta}\left(\bar{g}-\bar{g}^{*}\right)\right] \\
& \bar{c}=-\frac{\bar{g}^{w}}{2}-\frac{(1-n) \delta(1+\sigma)}{\sigma \delta(1+\sigma)+2 \sigma}\left[\left(g-g^{*}\right)+\frac{1}{\delta}\left(\bar{g}-\bar{g}^{*}\right)\right] \\
& y=g^{w}+\frac{\delta(1+\sigma)(1-n)}{\delta(1+\sigma)+2}\left[\left(g-g^{*}\right)+\frac{1}{\delta}\left(\bar{g}-\bar{g}^{*}\right)\right] \\
& \bar{y}=\frac{\bar{g}^{w}}{2}+\frac{\delta(1-n)}{\delta(1+\sigma)+2}\left[\left(g-g^{*}\right)+\frac{1}{\delta}\left(\bar{g}-\bar{g}^{*}\right)\right]
\end{aligned}
$$

Hence, the effects of temporary increases in government spending can be summarised as follows:

$$
\begin{array}{llrl}
\frac{\partial c}{\partial g}=-\frac{(1-n) \delta(1+\sigma)}{\sigma \delta(1+\sigma)+2 \sigma}<0 & \frac{\partial c}{\partial g^{*}} & =\frac{(1-n) \delta(1+\sigma)}{\sigma \delta(1+\sigma)+2 \sigma}>0 \\
\frac{\partial \bar{c}}{\partial g} & =-\frac{(1-n) \delta(1+\sigma)}{\sigma \delta(1+\sigma)+2 \sigma}<0 & \frac{\partial \bar{c}}{\partial g^{*}} & =\frac{(1-n) \delta(1+\sigma)}{\sigma \delta(1+\sigma)+2 \sigma}>0 \\
\frac{\partial y}{\partial g} & =n+\frac{\delta(1+\sigma)(1-n)}{\delta(1+\sigma)+2}>0 & \frac{\partial y}{\partial g^{*}} & =1-n-\frac{\delta(1+\sigma)(1-n)}{\delta(1+\sigma)+2}>0 \\
\frac{\partial \bar{y}}{\partial g} & =\frac{\delta(1-n)}{\delta(1+\sigma)+2}>0 & \frac{\partial \bar{y}}{\partial g^{*}} & =-\frac{\delta(1-n)}{\delta(1+\sigma)+2}<0
\end{array}
$$

While the multipliers of a permanent increase in government spending, such that $g=\bar{g}$; $g^{*}=\bar{g}^{*}$, will be:

$$
\begin{aligned}
\frac{\partial c}{\partial \bar{g}} & =-\frac{(1-n)(1+\delta)(1+\sigma)}{\sigma \delta(1+\sigma)+2 \sigma}<0 & \frac{\partial c}{\partial \bar{g}^{*}} & =\frac{(1-n)(1+\delta)(1+\sigma)}{\sigma \delta(1+\sigma)+2 \sigma}>0 \\
\frac{\partial \bar{c}}{\partial \bar{g}} & =-\left[\frac{n}{2}+\frac{(1-n)(1+\delta)(1+\sigma)}{\sigma \delta(1+\sigma)+2 \sigma}\right]<0 & \frac{\partial \bar{c}}{\partial \bar{g}^{*}} & =\frac{2+\delta(1+\sigma)(2-\sigma)}{\sigma \delta(1+\sigma)+2 \sigma} \\
\frac{\partial y}{\partial \bar{g}} & =n+\frac{(1-n)(1+\delta)(1+\sigma)}{\delta(1+\sigma)+2}>0 & \frac{\partial y}{\partial \bar{g}^{*}} & =1-n-\frac{(1+\delta)(1+\sigma)(1-n)}{\delta(1+\sigma)+2}<0 \\
\frac{\partial \bar{y}}{\partial \bar{g}} & =\frac{n}{2}+\frac{(1+\delta)(1-n)}{\delta(1+\sigma)+2}>0 & \frac{\partial \bar{y}}{\partial \bar{g}^{*}} & =\frac{(1-n) \delta(\sigma-1)}{\delta(1+\sigma)+2}>0
\end{aligned}
$$


For marginal changes in government spending, it is possible to calculate their welfare impact by substituting the results into the log-linear social utility function: ${ }^{21}$

$$
d U^{R}=c-\frac{\sigma-1}{\sigma} y+\frac{1}{\delta}\left(\bar{c}-\frac{\sigma-1}{\sigma} \bar{y}\right)
$$

to obtain:

$$
d U^{R}=-\frac{\sigma-n}{2 \sigma}\left[2 g+\frac{(2 \sigma-n)}{(\sigma-n) \delta} \bar{g}\right]+\frac{(1-n)}{2 \sigma}\left[2 g^{*}+\frac{1}{\delta} \bar{g}^{*}\right]
$$

\section{A.2 Fixed Exchange Rate Redux}

In the fixed exchange rate regime, the exchange rate is kept constant both in the short and in the long run, such that $e=\bar{e}=0$. Except for this constraint, the log-linearised equations of the model are the same given in section 3. From the money demand equations this implies that:

$$
m-m^{*}=c-c^{*}
$$

Since PPP holds, the other immediate implications of exchange rate stability are:

$$
\begin{aligned}
& p=p^{*}=0 \\
& \bar{p}=\bar{p}^{*}
\end{aligned}
$$

Subtracting now the two $S R$-current account equations gives:

$$
\bar{b}=(1-n)\left[\left(y-y^{*}\right)-\left(c-c^{*}\right)-\left(g-g^{*}\right)\right]
$$

Subtracting also the $L R$-current account equations, it is possible to write:

$$
\bar{c}-\bar{c}^{*}=\frac{1}{1-n} \delta \bar{b}+\bar{y}-\bar{y}^{*}-\left[\bar{p}^{*}(f)-\bar{p}(h)\right]-\left(\bar{g}-\bar{g}^{*}\right)
$$

As in the flexible exchange rate version of the model, the log-linearised system implies that:

$$
\begin{aligned}
\bar{b} & =(1-n)\left[\left(y-y^{*}\right)-\left(c-c^{*}\right)-\left(g-g^{*}\right)\right] \\
y-y^{*} & =\sigma e \\
\bar{y}-\bar{y}^{*} & =\sigma\left[\bar{e}+\bar{p}^{*}(f)-\bar{p}(h)\right] \\
\bar{y}-\bar{y}^{*} & =-\frac{\sigma}{1+\sigma}\left(\bar{c}-\bar{c}^{*}\right)
\end{aligned}
$$

\footnotetext{
${ }^{21}$ Note that $\bar{y}_{0}=\left(\frac{\sigma-1}{\sigma k_{0}}\right)^{\frac{1}{2}}$.
} 
Notice that in this regime short-run relative output remains constant:

$$
\left(y-y^{*}\right)_{f i x}=\sigma e=0
$$

Replacing these results in the difference of the $L R$-current accounts (3), taking into account that $e=\bar{e}=0$, gives:

$$
\bar{b}=\frac{2 \sigma(1-n)}{\delta(1+\sigma)}\left(\bar{c}-\bar{c}^{*}\right)+\frac{(1-n)}{\delta}\left(\bar{g}-\bar{g}^{*}\right)
$$

Substituting now $\bar{b}$ in the difference of the $S R$-current accounts $(2)$, recalling that $\bar{c}-\bar{c}^{*}=$ $c-c^{*}$ yields:

$$
\left(c-c^{*}\right)_{f i x}=\left(\bar{c}-\bar{c}^{*}\right)_{f i x}=-\frac{\delta(1+\sigma)}{\delta(1+\sigma)+2 \sigma}\left[g-g^{*}+\frac{1}{\delta}\left(\bar{g}-\bar{g}^{*}\right)\right]
$$

Long-run relative output can be obtained by replacing $\left(\bar{c}-\bar{c}^{*}\right)$ into the labour-leisure tradeoff equation:

$$
\left(\bar{y}-\bar{y}^{*}\right)_{f i x}=-\frac{\sigma}{1+\sigma}\left(\bar{c}-\bar{c}^{*}\right)_{f i x}=\frac{\delta \sigma}{\delta(1+\sigma)+2 \sigma}\left[g-g^{*}+\frac{1}{\delta}\left(\bar{g}-\bar{g}^{*}\right)\right]
$$

The multipliers for a fiscal expansion in the fixed exchange rate regime can be compared to those obtained in the flexible exchange rate version of the model:

$$
\begin{aligned}
-\left.\frac{\partial\left(c-c^{*}\right)}{\partial\left(g-g^{*}\right)}\right|_{f i x} & =\frac{\delta(1+\sigma)}{\delta(1+\sigma)+2 \sigma}>-\left.\frac{\partial\left(c-c^{*}\right)}{\partial\left(g-g^{*}\right)}\right|_{f l e x} \\
& \left.\frac{\partial\left(y-y^{*}\right)}{\partial\left(g-g^{*}\right)}\right|_{f i x}=0 \quad<\left.\frac{\partial\left(y-y^{*}\right)}{\partial\left(g-g^{*}\right)}\right|_{f l e x} \\
-\left.\frac{\partial\left(\bar{c}-\bar{c}^{*}\right)}{\partial\left(g-g^{*}\right)}\right|_{f i x} & =\frac{\delta(1+\sigma)}{\delta(1+\sigma)+2 \sigma}>-\left.\frac{\partial\left(c-c^{*}\right)}{\partial\left(g-g^{*}\right)}\right|_{f l e x} \\
\left.\frac{\partial\left(\bar{y}-\bar{y}^{*}\right)}{\partial\left(g-g^{*}\right)}\right|_{f i x} & =\frac{\delta \sigma}{\delta(1+\sigma)+2 \sigma}>\left.\frac{\partial\left(\bar{y}-\bar{y}^{*}\right)}{\partial\left(g-g^{*}\right)}\right|_{\text {flex }}
\end{aligned}
$$

Recall now that the fixed exchange rate requirement implied that $m-m^{*}=c-c^{*}$. Hence:

$$
m-m^{*}=-\frac{\delta(1+\sigma)}{\delta(1+\sigma)+2 \sigma}\left[g-g^{*}+\frac{1}{\delta}\left(\bar{g}-\bar{g}^{*}\right)\right]
$$

Aggregate consumption depends on the type of the monetary arrangement. Since the aim is not to compare different types of fixed exchange rate regimes, we maintain the same 
assumption regarding the world money stock as under flexible exchange rates, that is $m^{w}=$ $\bar{m}^{w}=0$. Therefore:

$$
\begin{aligned}
r & =\frac{1+\delta}{\delta} \bar{c}^{w} \\
c^{w} & =0 \\
y^{w} & =c^{w}+g^{w}=g^{w}
\end{aligned}
$$

and

$$
\begin{aligned}
m & =\bar{m}^{w}+(1-n)\left(m-m^{*}\right)=-\frac{(1-n) \delta(1+\sigma)}{\delta(1+\sigma)+2 \sigma}\left[g-g^{*}+\frac{1}{\delta}\left(\bar{g}-\bar{g}^{*}\right)\right] \\
m^{*} & =\bar{m}^{w}-n\left(m-m^{*}\right)=\frac{n \delta(1+\sigma)}{\delta(1+\sigma)+2 \sigma}\left[g-g^{*}+\frac{1}{\delta}\left(\bar{g}-\bar{g}^{*}\right)\right]
\end{aligned}
$$

Once more we estimate the impact of marginal changes in government spending on welfare by substituting the results into the log-linear social utility function to obtain:

$$
d U_{f i x}^{R}=-\frac{\sigma-1}{\sigma} g^{w}-\frac{(2 \sigma-1)}{2 \sigma \delta} \bar{g}^{w}-(1-n)\left[\left(g-g^{*}\right)+\frac{1}{\delta}\left(\bar{g}-\bar{g}^{*}\right)\right]=d U^{R}
$$

\section{A.3 Effects of a Debt-Financed Tax-Cut in an Overlapping Generations Model}

Ganelli (2003b) gives the analytical results for the impact of a debt-financed tax cut on the exchange rate and relative output and consumption. The results for the impact on world aggregates can be inferred from the closed-economy model in Ganelli (2002), but the analytical results for the log-linearised model are calculated here. These enable us to find expressions for the overall effect on each country's consumption and output and allow us to run simulations to assess the overall impact of this policy on welfare. The log-linearised 
equilibrium equations of the model (derived in Ganelli, 2003b) can be summarised as follows:

$$
\begin{array}{ll}
y_{t}=\sigma\left[p_{t}-p_{t}(h)\right]+c_{t}^{w}+g_{t}^{w} & \text { market clearing } \\
p_{t}=n p_{t}(h)+(1-n)\left[e_{t}+p_{t}^{*}(h)\right] & \text { prices } \\
m_{t}-p_{t}=c_{t}-\frac{r_{t}}{R_{0}}-\frac{\bar{p}_{t}-p_{t}}{R_{0}-1} & \text { money demand } \\
(\sigma-1) y_{t}=-\psi \sigma\left(c_{t}+p_{t}-p_{t}(h)\right) & \text { labour-leisure trade-off } \\
\bar{c}=\frac{1-q \beta}{1+\chi+\psi}(1-q)(1+\psi) \frac{R_{0}}{R_{0}-q} \bar{h}+q \beta R_{0} c+q \beta\left(R_{0}-1\right) r & \text { Euler equation } \\
\bar{h}=-\left(\bar{p}_{t}-\bar{p}_{t}(h)\right)+\frac{1}{\theta(1+\psi)} \bar{y}-\frac{q\left(R_{0}-1\right)}{\left(R_{0}-q\right) R_{0}} \bar{r}-\frac{R_{0}-1}{1+\psi} \bar{d} & \text { LR financial wealth } \\
\bar{b}=-\left(p_{t}-p_{t}(h)\right)+y-c-g & \text { SR current account } \\
\bar{c}=\left(R_{0}-1\right) \bar{b}-(\bar{p}-\bar{p}(h))+\bar{y}-\bar{g} & \text { LR current account }
\end{array}
$$

where all variables are in deviations from the initial steady state; $R_{0}$ is the steady state level of the gross real interest rate, which is different from $\delta$; $\bar{d}$ is debt accumulation; $\psi$ is the weight of leisure in the utility function (the disutility of leisure is logarithmic in this model); $h$ is financial wealth accumulation; and $(1-q)$ is the probability of death; all remaining parameters are defined as before. Parallel conditions hold for the foreign economy. It can be shown (see Ganelli, 2003b) that the steady state level of the gross real interest rate must satisfy:

$$
R_{0}^{2}-\left[q+\frac{1}{q \beta}\left(1-\frac{1-q \beta}{1+\chi+\psi}(1-q)(1+\psi)\right)\right] R_{0}+\frac{1}{\beta}=0
$$

with the stable solution corresponding to the highest root (see Ganelli, 2002, for details). The policy being analysed is a tax-cut financed by debt accumulation, with long-run taxes increasing endogenously to meet interest payments. Hence:

$$
\left(R_{0}-1\right) \bar{d}=-\left(R_{0}-1\right) \tau=\bar{\tau}
$$

where $\tau$ are non-distortionary taxes. Aggregating the home and foreign labour-leisure tradeoff equations, it is possible to obtain:

$$
\bar{y}^{w}=-\psi \frac{\sigma}{\sigma-1} \bar{c}^{w}
$$


Aggregating the output demand equations:

$$
\bar{y}^{w}=\bar{c}^{w}+\bar{g}^{w}
$$

Hence

$$
\begin{aligned}
\bar{c}^{w} & =-\frac{\sigma-1}{\sigma-1+\psi \sigma} \bar{g}^{w} \\
\bar{y}^{w} & =\frac{\psi \sigma}{\sigma-1+\psi \sigma} \bar{g}^{w}
\end{aligned}
$$

Assuming that $\bar{g}^{w}=0$ (since the policy being analysed here is a debt-financed tax cut):

$$
\bar{c}^{w}=\bar{y}^{w}=0
$$

Substituting this result in the aggregation of the long-run Euler equation, it is possible to obtain the accumulation of wealth as a function of the long-run world real interest rate:

$$
\bar{h}^{w}=-\frac{q \beta\left(R_{0}-1\right)}{a_{1}} \bar{r}
$$

where $a_{1}=\frac{1-q \beta}{1+\chi+\psi}(1-q)(1+\psi) \frac{R_{0}}{R_{0}-q}$. In the aggregated short-run Euler equation, these results yield:

$$
c^{w}=-\left(\frac{a_{1} \bar{h}^{w}+q \beta\left(R_{0}-1\right) r}{q \beta R_{0}}\right)=\frac{R_{0}-1}{R_{0}}(\bar{r}-r)
$$

Taking now the aggregated short-run money demand equation:

$$
m^{w}=c^{w}-\frac{r}{R_{0}}-\frac{\bar{p}^{w}}{R_{0}-1}
$$

To eliminate $\bar{p}_{t}^{w}$, notice that in the long run:

$$
\bar{m}^{w}-\bar{p}^{w}=\bar{c}^{w}-\frac{\bar{r}}{R_{0}}
$$

Assuming that $m_{t}^{w}=\bar{m}_{t}^{w}=0$, since the focus now is on fiscal policy:

$$
\bar{p}^{w}=\frac{\bar{r}}{R_{0}}
$$

Substituting in equation (6):

$$
c^{w}=\frac{r}{R_{0}}+\frac{\bar{r}}{R_{0}\left(R_{0}-1\right)}
$$


which combined with equation (5) gives a relationship between the short- and the long-run real interest rate (in terms of deviations from the steady state):

$$
r=\frac{\left(R_{0}-1\right)^{2}-1}{R_{0}\left(R_{0}-1\right)} \bar{r}
$$

Substituting this result in (7) gives the short-run world consumption as a function of the long-run real interest rate:

$$
c^{w}=\frac{1}{R_{0}} \bar{r}
$$

The next step is to find an expression for the long-run real interest rate as a function of the policy variables. This can be done by looking at the aggregated equation for wealth accumulation, taking into account that $\bar{y}^{w}=0$ and using result (4):

$$
\begin{aligned}
\bar{h}^{w} & =-\frac{q\left(R_{0}-1\right)}{\left(R_{0}-q\right) R_{0}} \bar{r}-\frac{R_{0}-1}{1+\psi} \bar{d} \\
& \Longleftrightarrow \quad-\frac{q \beta\left(R_{0}-1\right)}{a_{1}} \bar{r}=-\frac{q\left(R_{0}-1\right)}{\left(R_{0}-q\right) R_{0}} \bar{r}-\frac{R_{0}-1}{1+\psi} \bar{d} \\
& \Longleftrightarrow q\left(R_{0}-1\right)\left[\frac{a_{1}-\beta\left(R_{0}-q\right) R_{0}}{a_{1}\left(R_{0}-q\right) R_{0}}\right] \bar{r}=-\frac{R_{0}-1}{1+\psi} \bar{d} \\
& \Longleftrightarrow \bar{r}=\frac{a_{1}\left(R_{0}-q\right) R_{0}}{\beta\left(R_{0}-q\right) R_{0}-a_{1}} \frac{R_{0}-1}{q\left(R_{0}-1\right)(1+\psi)} \bar{d} \\
& \Longleftrightarrow \bar{r}=a_{5} \frac{R_{0}-1}{q\left(R_{0}-1\right)(1+\psi)} \bar{d}
\end{aligned}
$$

where $a_{5}=\frac{a_{1}\left(R_{0}-q\right) R_{0}}{\beta\left(R_{0}-q\right) R_{0}-a_{1}}$. Since from the steady-state equilibrium condition for $R_{0}$, it can be shown that $R_{0}=\frac{1-a_{1}}{q \beta}$, it is simple to show that $a_{5}$ is always positive:

$$
\beta\left(R_{0}-q\right) R_{0}-a_{1}>0 \Rightarrow R_{0}^{2}>\frac{1}{\beta}
$$

This is always satisfied since in the stable steady-state solution $R_{0}>\frac{1}{\beta}$ and $\beta<1$. Hence (taking into account the market clearing equations and the assumption that $g^{w}=0$ ):

$$
c^{w}=y^{w}=\frac{a_{5}}{q R_{0}(1+\psi)} \bar{d}
$$


The baseline parameters used for the simulations are:

$$
\begin{aligned}
q & =0.7 ; \\
\beta & =0.95 ; \\
\chi & =1 ; \\
\psi & =1 ; \\
\sigma & =7.5 ; \\
n & =0.5 ; \\
\bar{d} & =1 ; \\
\bar{d}^{*} & =0 ; \\
g & =g^{*}=0 ;
\end{aligned}
$$

The choice of $\beta$ corresponds to a long-run real interest rate of $5 \%$. The degree of monopolistic competition $\sigma$ was chosen to be approximately equal to that set by Rotemberg and Woodford (1998). ${ }^{22}$ Changing $\chi$ and $\psi$ does not change the results significantly (even if they take values lower than one). Social welfare was assumed to take the form:

$$
W=U+\frac{q \beta}{1-q \beta} \bar{U}
$$

This corresponds to evaluating the welfare of a representative agent of generation $a$ using per capita values for consumption and employment.

\footnotetext{
${ }^{22}$ They chose $\sigma=7.66$, which implies an average mark-up of $15 \%$.
} 
Figure 1: Effects of a debt-financed tax cut as the probability of staying alive, q, increases.
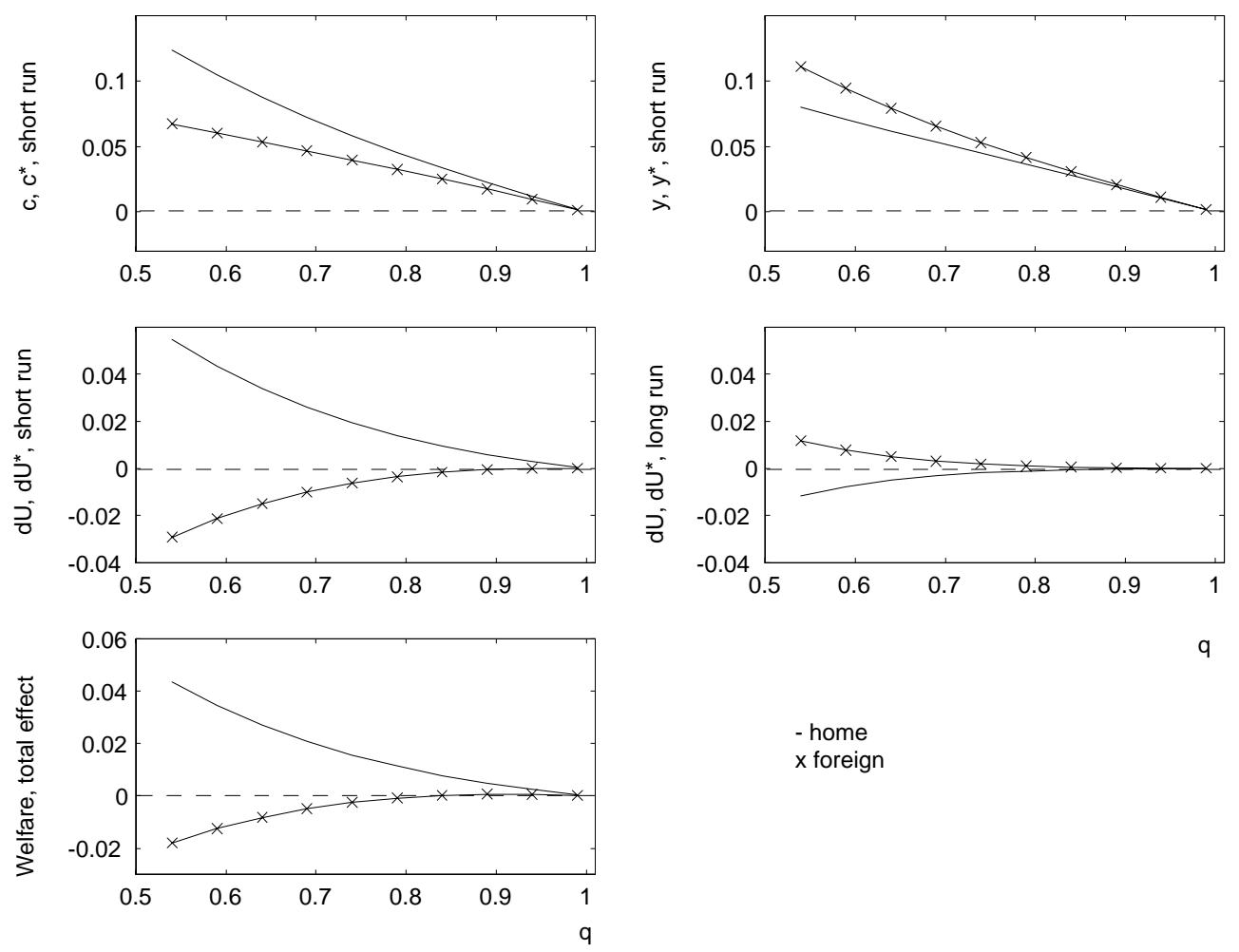

$q$

- home $x$ foreign 
Figure 2: Effects of a debt-financed tax cut as competition increases (as the elasticity of substitution between varieties, $\sigma$, increases).
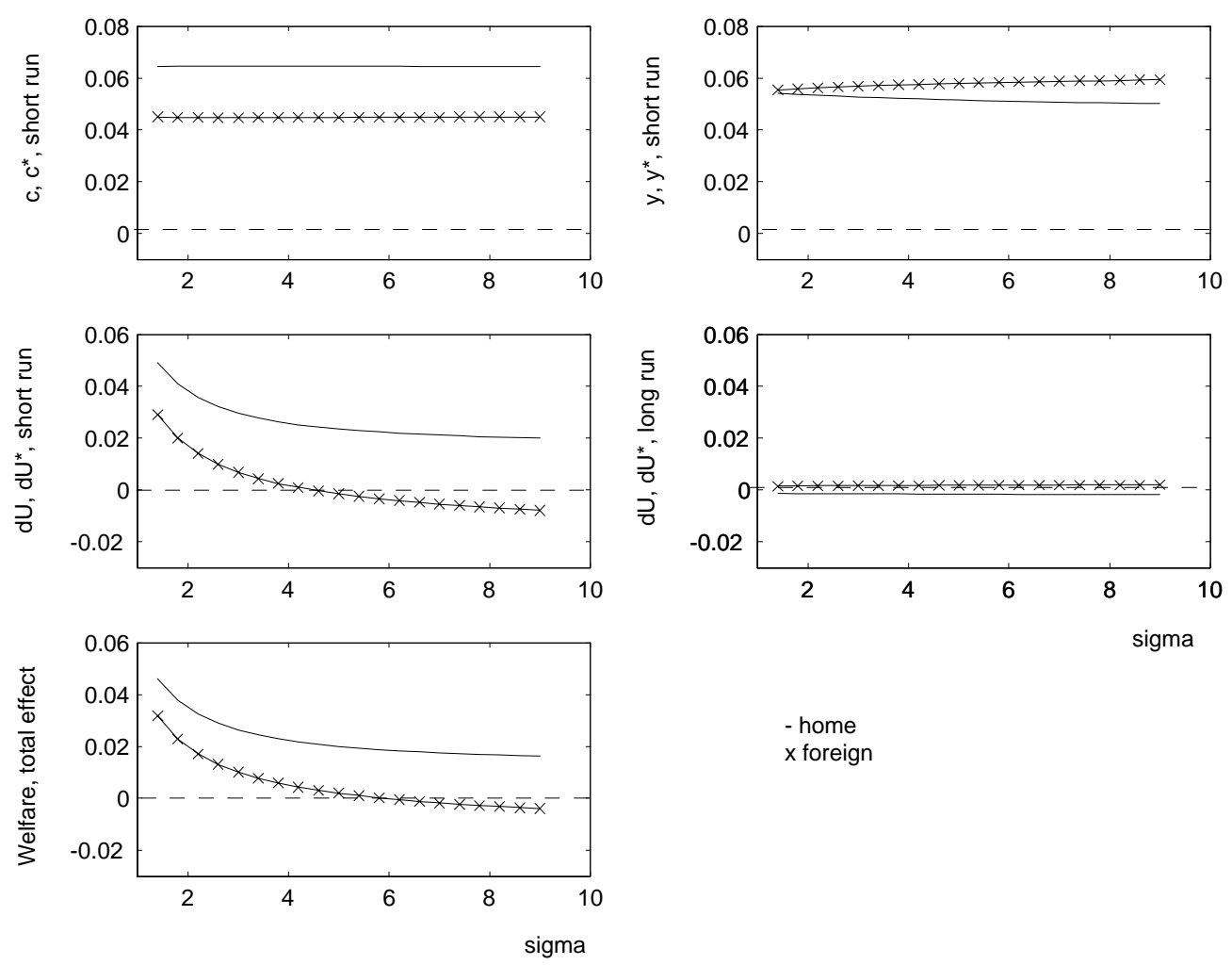

- home $x$ foreign 
Figure 3: Effects of a debt-financed tax cut as the size of the home country, n, increases.
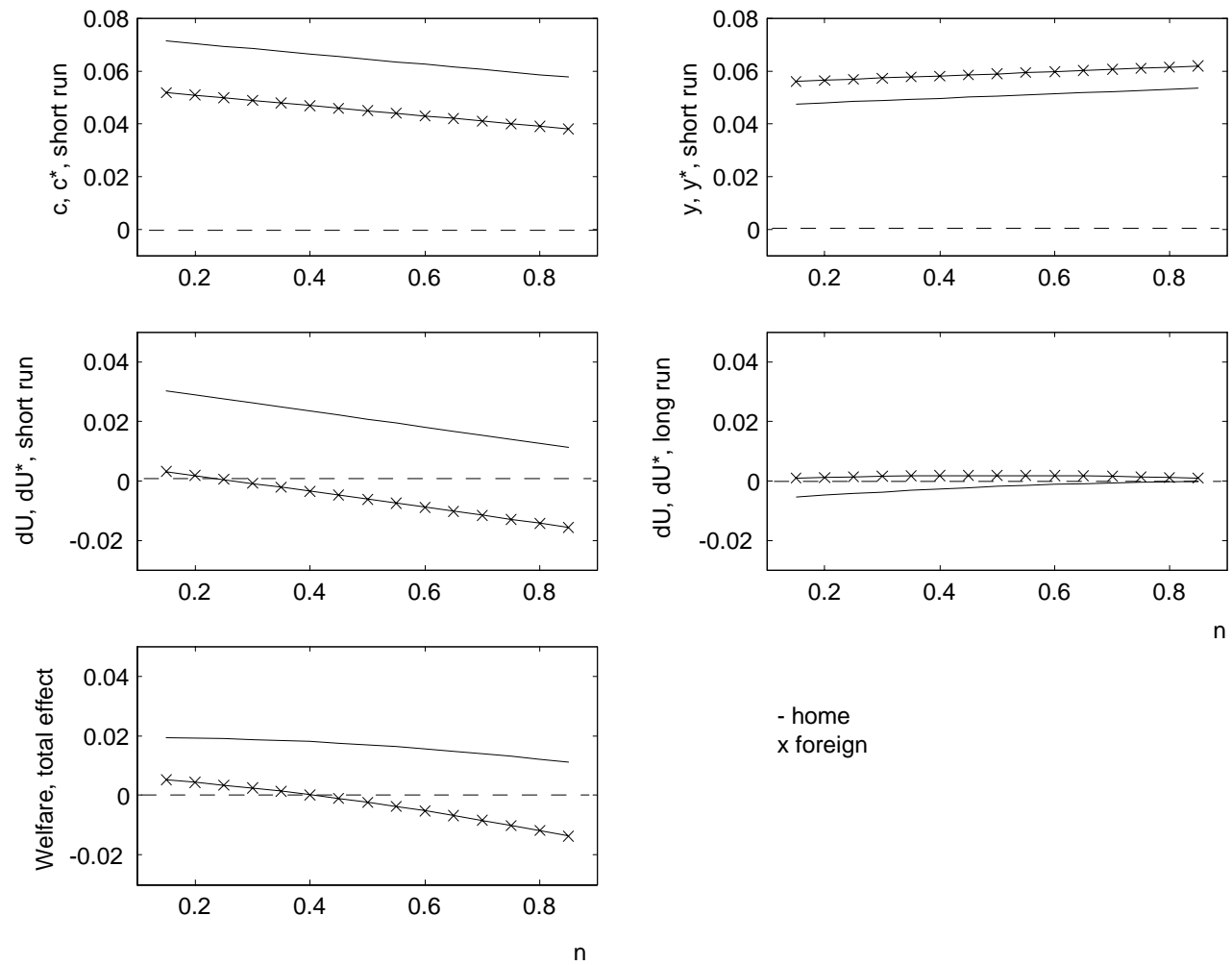

- home

$x$ foreign 


\section{ABOUT CEPS}

$\mathrm{F}$ ounded in 1983, the Centre for European Policy Studies is an independent policy research institute dedicated to producing sound policy research leading to constructive solutions to the challenges facing Europe today. Funding is obtained from membership fees, contributions from official institutions (European Commission, other international and multilateral institutions, and national bodies), foundation grants, project research, conferences fees and publication sales.

\section{GOALS}

- To achieve high standards of academic excellence and maintain unqualified independence.

- To provide a forum for discussion among all stakeholders in the European policy process.

- To build collaborative networks of researchers, policy-makers and business across the whole of Europe.

- To disseminate our findings and views through a regular flow of publications and public events.

\section{ASSETS AND ACHIEVEMENTS}

- Complete independence to set its own priorities and freedom from any outside influence.

- Authoritative research by an international staff with a demonstrated capability to analyse policy questions and anticipate trends well before they become topics of general public discussion.

- Formation of seven different research networks, comprising some 140 research institutes from throughout Europe and beyond, to complement and consolidate our research expertise and to greatly extend our reach in a wide range of areas from agricultural and security policy to climate change, justice and home affairs and economic analysis.

- An extensive network of external collaborators, including some 35 senior associates with extensive working experience in EU affairs.

\section{Programme Structure}

CEPS is a place where creative and authoritative specialists reflect and comment on the problems and opportunities facing Europe today. This is evidenced by the depth and originality of its publications and the talent and prescience of its expanding research staff. The CEPS research programme is organised under two major headings:

\section{Economic Policy}

Macroeconomic Policy

European Network of Economic Policy Research Institutes (ENEPRI)

Financial Markets, Company Law \& Taxation

European Credit Research Institute (ECRI)

Trade Developments \& Policy

Energy, Environment \& Climate Change

Agricultural Policy

\author{
Politics, Institutions and Security \\ The Future of Europe \\ Justice and Home Affairs \\ The Wider Europe \\ South East Europe \\ Caucasus \& Black Sea \\ EU-Russian/Ukraine Relations \\ Mediterranean \& Middle East \\ CEPS-IISS European Security Forum
}

In addition to these two sets of research programmes, the Centre organises a variety of activities within the CEPS Policy Forum. These include CEPS task forces, lunchtime membership meetings, network meetings abroad, board-level briefings for CEPS corporate members, conferences, training seminars, major annual events (e.g. the CEPS International Advisory Council) and internet and media relations. 